\title{
SENSITIVITY STUDY OF PLANETARY BOUNDARY LAYER PARAMETERIZATION SCHEMES FOR THE SIMULATION OF TROPICAL CYCLONE 'FANI' OVER THE BAY OF BENGAL USING HIGH RESOLUTION WRF-ARW MODEL
}

\author{
M. M. Alam \\ Department of Physics, Khulna University of Engineering \& Technology, Khulna - 9203
}

Received: 16 August 2020

Accepted: 15 October 2020

\begin{abstract}
Comprehensive sensitivity analyses on physical parameterization schemes of WRF-ARW (V3.8.1) model have been carried out for the simulation of Tropical Cyclone (TC) Fani that formed in the Bay of Bengal (BoB) and crossed the Bangladesh and Odisha coast of India on 3rd May 2019. Global Forecasting System (GFS) data $1^{0}$ and $0.25^{\circ}$ from National Centre for Environment Prediction (NCEP) is used as initial and lateral boundary conditions. The six different Planetary Boundary Layer (PBL) schemes used in this research are YSU, BouLac, $T E M F$, Shin-Hong, GBM and MRF. The meteorological parameters, which have been studied to identify the effect of PBL during the propagation and movement of TC Fani are Estimated Central Pressure (ECP), Maximum Wind Speed (MWS) at $10 \mathrm{~m}$ height, average relative humidity $(\%)$, temperature $\left({ }^{\circ} \mathrm{C}\right)$ and potential temperature $\left({ }^{\circ} \mathrm{K}\right)$ at $2 \mathrm{~m}$ height, Modified Convective Available Potential Energy (MCAP), average PBL height and average high clouds (\%). The area considered for these averages are $82-92{ }^{\circ} \mathrm{E}$ and $7-22^{\circ} \mathrm{N}$ inside the model domain. The simulated ECP by TEMF scheme are 930, 932, 937, 929, 944 and 932 hPa for the Initial Conditions (ICs) at 0000 UTC of 27, 28, 29, 30 April, and 01 May and 02 May, respectively and observed ECP was $932 \mathrm{hPa}$. The intensity of pressure fall by the TEMF scheme is similar to that observed up to the time of crossing the land of TC Fani. The MWS simulated by the TEMF scheme is almost similar to that of the observed MWS at $10 \mathrm{~m}$ height and all other schemes have simulated much lower MWS. The temperature at $2 \mathrm{~m}$ height is positively correlated with the ECP and MWS at $10 \mathrm{~m}$ height. The TEMF scheme has simulated maximum high clouds for all ICs and for all through the simulation time. The error was systematic for all PBL schemes for the ICs at 0000 UTC of 30 April at $0.25^{\circ}$ and $1^{\circ}$ GFS data but the track error was much less for $1^{\circ}$ GFS data than that of $0.25^{\circ}$ GFS data. The TEMF scheme has simulated the most deviated track and MRF scheme has simulated less deviated track for all through the simulation. The study has shown large variations of track and intensity among the different PBL schemes. The PBL schemes have a major impact on the track and intensity of TC Fani. The intensity simulated by the TEMF scheme is better but the track error is higher than that of other schemes.
\end{abstract}

Keywords: PBL parameterizations; Tropical Cyclone; Maximum Wind Speed; Estimated Central Pressure; Microphysics; Sensitivity.

\section{INTRODUCTION}

The Planetary Boundary Layer (PBL) is the lower part of the troposphere with thickness ranging from a few hundred meters to a few kilometers within which the effects of the Earth's surface are felt by the atmosphere. It has the characteristic of having a quick response to change in surface radiation. The most prominent of such change in surface radiation is the diurnal cycle. Surface radiation is found to be maxima during the day and minima during the night. As the day progresses the solar heating with thermals raising upwards an amount of turbulence in the boundary layer increases. The moisture and momentum are not frequently well mixed but the potential temperature is frequently well mixed in the absence of clouds.

PBL schemes were developed to facilitate determining the turbulent fluxes of moisture, heat, and momentum in the boundary layer. However, due to the complex nature of turbulence, closure has remained a problem. Holt and Raman (1988) evaluated 11 PBL schemes with 1-D barotropic boundary layer model. They accomplished that the mean boundary layer structure is hardly sensitive to the order of the closure, while the turbulent structure is better represented using the Total Kinetic Energy (TKE) closure. The turbulent diffusivities profiles are quite insensitive (sensitive) to PBL parameterizations, but the resultant mean wind and thermodynamic variables are quite variable (invariable) depending on PBL parameterization schemes (Musson-Genon, 1995; Sharan and Gopalakrishnan, 1997). Hu et al. (2010) compared with surface and boundary layer observations with three different PBL schemes over south-central US during summer 2005. They showed that the simulations with the YSU and ACM2 schemes provide much less bias than with the MYJ scheme.

Dong et al. (2019) studied the sensitivity to PBL parameterization to investigate the boundary layer structure and rainfall after landfall of Typhoon Fitow (2013). In their study the impact of vertical diffusivity in the PBL 
parameterization on the boundary layer structure of land falling typhoon and its process are revealed. The PBL parameterization schemes are important for cloud microphysics schemes in forecasting hurricane intensity and accompanying precipitation ( $\mathrm{Li}$ and $\mathrm{Pu}, 2008$ ). Shin and Dudhia (2016) studied on the evaluation of PBL parameterizations in WRF at sub-kilometer grid spacing using four nonlocal parameterizations schemes include - YSU, ACM2, Eddy Diffusivity Mass Flux (EDMF), and Total Energy Mass Flux (TEMF) - and the MYNN scheme. Their results have suggested that the TEMF experiment computes the largest sub grid space (SGS) momentum transport, while it calculates the smallest SGS heat transport.

Das and Alam (2019) studied on the impact on environmental moisture during the intensification and movement of TC Hudhud in the BoB using WSM6, WDM6, Thompson and NSSL mom-1 microphysics schemes of WRFARW Model. They found that the average track error was minima and intensity in terms of pressure fall and maximum wind speed were the better results for WDM6 scheme. Haney et al. (2018) studied the sensitivity of microphysics (MP) for the simulation of heavy rainfall events all over Bangladesh using 12 different MP schemes. The microphysics schemes are Kessler, Lin et al., WSM3, Ferrier, WSM6, Thomson graupel, MYDM, MDM, CAM V5.12-Moment 5 class, SBU, WDM6 and NSSL2 schemes. They perceived that SBU, WDM6, Lin, TH and WSM6 schemes have simulated similar amounts of rainfall in the heavy rainfall area of Bangladesh. Khan and Alam (2020) studied the sensitivity of MPs for the simulation of monthly rainfall using 24, 48 and 72-hour prediction over Bangladesh using WRF-ARW model. They proposed that as the forecast time increased the amount of total rain and heavy rain would increase for all MPs. WDM6 scheme gives the better performance of rainfall and rainy days all over Bangladesh.

Shin and Hong (2011) compared the five PBL schemes in the WRF model for a single day from the Cooperative Atmosphere-Surface Exchange Study (CASES-99) field program. They found the significant biases of wind components and are more divergent at nighttime. The local TKE closure schemes show better performance in stable conditions and non-local schemes are favorable in unstable conditions. The sensitivity of various PBL schemes (Cohen et al., 2015) in WRF Model have been evaluated to depict turbulent mixing for the application to a severe weather environment in the Southeastern US cold season. They observed that the local schemes only permit nearby model layers and nonlocal schemes consider the effect of larger eddies on the dispersion of heat, moisture, and momentum throughout the depth of the PBL.

Tyagi et al. (2018) studied the performance of PBL schemes in WRF modeling set up over Southern Italy by using ACM2, MRF and YSU first-order and MYJ, UW, MYNN2, and BouLac TKE closure schemes. The performance analysis of these schemes has been investigated by validating air temperature, specific humidity, wind speed, wind direction and PBL height to assess their efficiency in terms of the reproduction of observed weather conditions. Their results suggested that the TKE closure schemes perform better than first-order closure schemes, and the MYNN2 closure scheme is close to observed values most of the time. Braun and Tao (2000) studied the sensitivity of Hurricane Bob by using bulk aerodynamic, Blackadar, MRF, and Burk-Thompson boundary layer PBL schemes. They have observed that the minimum central pressures vary up to $16 \mathrm{hPa}$ and maximum winds by $15 \mathrm{~m} / \mathrm{s}$. Their study revealed that the Burk-Thompson and bulk aerodynamic boundary layer schemes produced the strongest storms while the MRF scheme produced the weakest storm.

In this research six different PBL parameterization schemes are investigating in an Advanced Research WRF (ARW) model to simulate the different meteorological parameters of Very Severe Cyclonic Storm (VSCS) Fani that formed in the Bay of Bengal $(\mathrm{BoB})$ and crossed Odisha coast of India and Bangladesh coast on 3rd May 2019. The six different PBL schemes are Yonsei University (YSU) scheme, Bougeault-Lacarrère (BouLac), Total Energy-Mass Flux (TEMF), Shin-Hong, Grenier-Bretherton-McCaa (GBM) and MRF. The studied meteorological parameters of TC Fani are estimated Central Pressure (ECP), maximum wind speed (MWS) at $10 \mathrm{~m}$ height, area averaged Temperature, potential temperature and relative humidity at $2 \mathrm{~m}$ height, area averaged MCAPE, area averaged PBL height and area averaged high cloud. The track of TC Fani is also studied on the basis of 30 April initial conditions (ICs).

\section{DATA AND METHODOLOGY}

\subsection{Life History of TC Fani}

Extremely Severe Cyclonic Storm (ESCS) 'Fani' originated from a low-pressure area which formed over east Equatorial Indian Ocean (EIO) and adjoining southeast BoB at 0000 UTC of 25 April. Under favorable environmental conditions, it concentrated into a Depression at 0300 UTC on 26 April over the same region. It intensified into a deep depression (DD) at 0000 UTC and further intensified into a Cyclonic Storm (CS) 'Fani' at around 0600 UTC of 27 April over southeast BoB. The TC Fani moved north-northwestwards and intensified, into a Severe Cyclonic Storm (SCS) at 1200 UTC of 29 April over central parts of south BoB. The TC moved nearly northwards and further intensified into a Very Severe Cyclonic Storm (VSCS) at 0000 UTC of 30 April over southwest BoB. The TC Fani moved northwestwards and further intensified into an ESCS at 1200UTC of 
30 over west central and adjoining southwest BoB. It started re-curving north-northeast wards at 0000 UTC 1 st May. It temporarily intensified during $0900-2100$ UTC on 02 May reaching the peak intensity of 115 knots. Thereafter from 03 May at 0000 UTC the TC weakened slightly. It continued to move north-northeast wards and crossed Odisha coast close to Puri as an ESCS with maximum sustained wind speed of 175-185 kmph gusting to $205 \mathrm{kmph}$ between 0230 to 0430 UTC of 03 May 2019. It weakened into a DD at 0300UTC over Bangladesh and adjoining Gangetic West Bengal and into a Depression over Bangladesh about 120 km northnorthwest of Dhaka around 0600UTC of 04 May.

\subsection{METHODOLOGY}

In the present study WRF-ARW version 3.8.1 model has been used to simulate the TC Fani that formed in the BoB. GFS data $1^{\circ} \times 1^{\circ}$ and $0.25^{\circ} \times 0.25^{\circ}$ for the 0000 UTC ICs of 27, 28, 29, 30 April and 01 and 02 May collected from NCEP is used as initial and Lateral Boundary Conditions (LBCs). The WRF-ARW model was run for 192, 168, 144, 120, 96 and 72 hours for the 0000 UTC ICs of 27, 28, 29, 30 April and 01 and 02 May, respectively. 6-hourly interval data are used for all initial conditions (ICs).

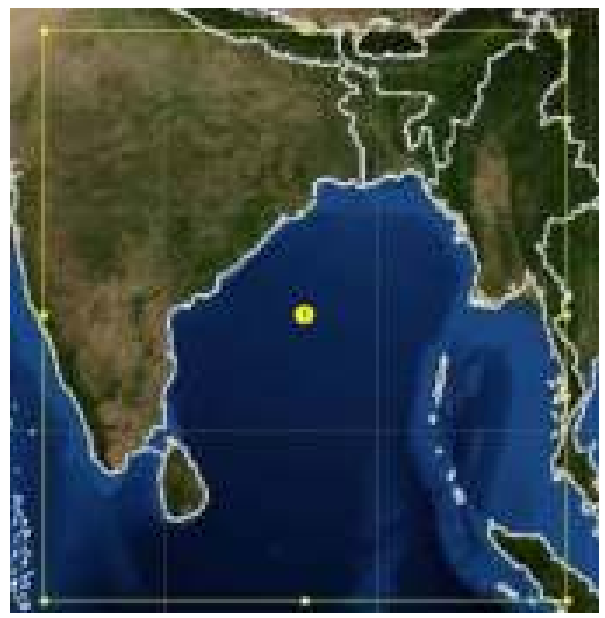

Figure 1: WRF-ARW Model Domain

Table 1: WRF-ARW Model and Domain Configurations

\begin{tabular}{ll}
\hline Dynamics & Non-hydrostatic \\
Number of domain & 1 \\
Horizontal grid distance & $9 \mathrm{~km}$ \\
Integration time step & $45 \mathrm{~s}$ \\
Number of grid points & X-direction 214 points, Y-direction 259 points \\
Microphysics & WDM 6 scheme (Hong et al. 2004). \\
Radiation scheme & Dudhia (Dudhia, 1989) for short wave radiation/ RRTM \\
& long wave Mlawer et al. (1997) \\
Surface layer & Monin- Obukhov similarity theory scheme (Hong and \\
& Pan, 1996) \\
Land surface parameterization & 5 Layer Thermal diffusion schemes (Ek et al., 2003) \\
Cumulus parameterization schemes & Kain-Fritsch (KF) scheme (Kain and Fritsch, 1990, 1993; \\
& Kain, 2004) \\
PBL parameterization & i) Yonsei University (Hong et al., 2006) \\
& ii) BouLac (Bougeault and Lacarrere, 1989) \\
& iii) TEMF (Angevine, 2005; Angevine et al., 2010) \\
& iv) Shin-Hong (Shin and Hong, 2013) \\
& v) GBM (Grenier and Bretherton, 2001) and \\
& vi) MRF (Hong and Pan, 1996) schemes \\
\hline
\end{tabular}

The NCEP GFS data is interpolated to the model horizontal and vertical grids and the model was integrated 192 , 168, 144, 120, 96 and 72 hours for TC Fani. 36 experiments have been conducted by using six different PBL schemes (e.g., YSU, BouLac, TEMF, Shin-Hong, GBM and MRF) in combinations with WRF Double-Moment 6-class (WDM6) microphysics scheme and KF cumulus parameterization scheme with different ICs. In this regard, the ICs of 0000 UTC of 27, 28, 29, 30 April and 1st and 2nd May 2019 data have been simulated and analyzed for TC Fani. The meteorological parameters are ECP, MWS at 10m height, area averaged relative 
humidity $(\%)$, temperature $\left({ }^{\circ} \mathrm{C}\right)$ and potential temperature $\left({ }^{0} \mathrm{~K}\right)$ at $2 \mathrm{~m}$ height, modified CAPE $(\mathrm{J} / \mathrm{kg})$, area averaged PBL height $(\mathrm{m})$ and area averaged high cloud $(\%)$ have been simulated and analyzed. The area considered for these averages are $82-92^{\circ} \mathrm{E}$ and $7-22^{\circ} \mathrm{N}$ inside the model domain. Simulated track and intensity have also been compared with the India Meteorological Department (IMD) observed results. The model domain is given in Figure 1 and domain configuration is given in Table 1.

\section{RESULTS AND DISCUSSION}

To understand the genesis, characteristics and structure of TC Fani, the different meteorological parameters have been simulated and analyzed since the formation of dissipation over land. The analyzed meteorological parameters are ECP, MWS at $10 \mathrm{~m}$ height, intensity, area averaged relative humidity (\%) at $2 \mathrm{~m}$ height, area averaged temperature $\left({ }^{\circ} \mathrm{C}\right)$ at $2 \mathrm{~m}$ height, area averaged potential temperature $\left({ }^{\circ} \mathrm{K}\right)$ at $2 \mathrm{~m}$ height, MCAPE $(\mathrm{J} / \mathrm{kg})$, area averaged PBL height and area averaged high cloud (\%). The track of TC Fani is also studied with the ICs of 30 April. The area considered for these averages are $82-92{ }^{\circ} \mathrm{E}$ and $7-22{ }^{\circ} \mathrm{N}$ inside the model domain. For the same type of meteorological parameters, the figures for $1^{\circ}$ and $0.25^{\circ} \mathrm{GFS}$ data are almost similar. Due to the similarity of the figures for $1^{\circ}$ and $0.25^{\circ} \mathrm{GFS}$ data the figures are presented only for $1^{\circ}$ GFS data but the analyses are presented for $1^{\circ}$ and $0.25^{\circ} \mathrm{GFS}$ data in the following subsection.

\subsection{Estimated Central Pressure (ECP)}

Time variation of IMD observed and simulated ECP by six different PBL schemes for the initial conditions (IC) at 0000 UTC of 27, 28, 29, 30 April, and 01 May and 02 May 2019 GFS data of $1^{o} \times 1^{o}$ in combination with WDM6 and KF scheme are presented in Figures 2(a-f) respectively. In Figures 2(a-f) MRF scheme has simulated lowest ECP and TEMF scheme has simulated highest ECP for all the ICs. The observed ECP and simulated TEMF scheme is almost matched for the ICs of 27 and 28 April up to 1800 UTC of 2nd May. After that it decreased continuously with the ICs of 27 and increased for ICs on 28 April but the pressure fell much higher than that observed.

The ECP of observed and TEMF scheme is almost matched with the ICs of 29, 30 April, and 01 May and 02 May but after 0600 UTC of 3rd May the intensity of pressure falls much higher than that of observed. When the cyclone is weakening the observed ECP is almost matched with the simulated ECP of all other PBL schemes but at the time of intensification the simulated ECP is almost matched with the TEMF scheme. The simulated ECP for $1^{\circ} \mathrm{GFS}$ data [Figures 2(a-f)] at the time of observed minimum ECP (932 hPa) were 957, 957, 978, 966,967 and $962 \mathrm{hPa} ; 963,955,972,968,963$ and $963 \mathrm{hPa} ; 935,932,934,930,946$ and $939 \mathrm{hPa} ; 962,962,968,968$, 965 and $958 \mathrm{hPa} ; 970,964,967,962,968$ and $963 \mathrm{hPa}$; 981, 975, 972, 976, 970 and $961 \mathrm{hPa}$ for YSU, BouLac, TEMF, Shin-Hong, GBM and MRF PBL schemes, respectively with the ICs at 0000 UTC of 27, 28, 29, 30 April, and 01 May and 02 May 2019.

The simulated ECP for $0.25^{\circ} \mathrm{GFS}$ data at the time of observed minimum ECP (932 hPa) were 971, 957, 969, 963, 966 and $952 \mathrm{hPa}$; 969, 957, 964, 961, 961 and $949 \mathrm{hPa} ; 930,932,937,929,944$ and $932 \mathrm{hPa}$; 966, 949, 957, 967, 961 and $949 \mathrm{hPa} ; 967,970,971,965,961$ and $952 \mathrm{hPa} ; 977,979,965,971,968$ and $953 \mathrm{hPa}$ for YSU, BouLac, TEMF, Shin-Hong, GBM and MRF schemes respectively with the ICs at 0000 UTC of 27, 28, 29, 30 April, and 01 May and 02 May 2019. Some PBL schemes have simulated lowest ECP for other times for different ICs but not so different except the TEMF scheme. From the simulated ECP it is seen that only the TEMF scheme has simulated close to the observed to that of observed ECP and other schemes overestimates than that of observed ECP.

The simulated ECP has been overestimated by $1^{\circ}$ than that of $0.25^{\circ}$ GFS data for YSU, BouLac and Shin-Hong schemes for almost all the ICs and all through the simulation time with little exceptions. TEMF and GBM schemes have underestimated ECP with the ICs of 27, 28, 29 and 30 April and higher ECP with the ICs of 1st and 2nd May 2019 by $1^{\circ}$ GFS data than that of $0.25^{\circ}$ GFS data almost although the simulation time. MRF scheme has simulated lower ECP with the ICs of 27, 28 and 29 April up to 0000 UTC of 2nd May and higher ECP with the ICs of 30 April, 1st and 2nd May 2019 by $1^{\circ}$ than that of $0.25^{\circ}$ GFS data almost although the simulation time. After the landfall the simulated ECP for almost all PBL schemes followed the pattern of observed ECP for GFS data but the output of GFS data is different from that of observed. The intensity of pressure fall by the TEMF scheme is similar to that observed up to the time of crossing the land of TC Fani. The deviation of ECP between $1^{\circ}$ and $0.25^{\circ}$ output of the TEMF scheme is much higher after the landfall of TC Fani. 

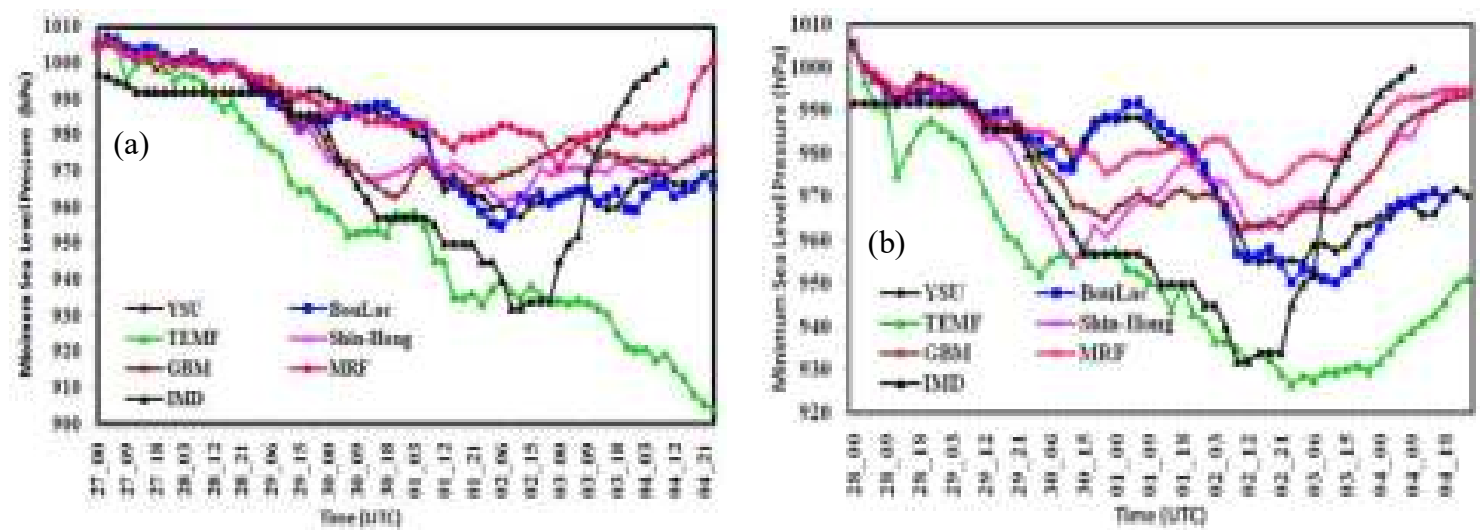

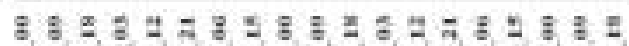
F

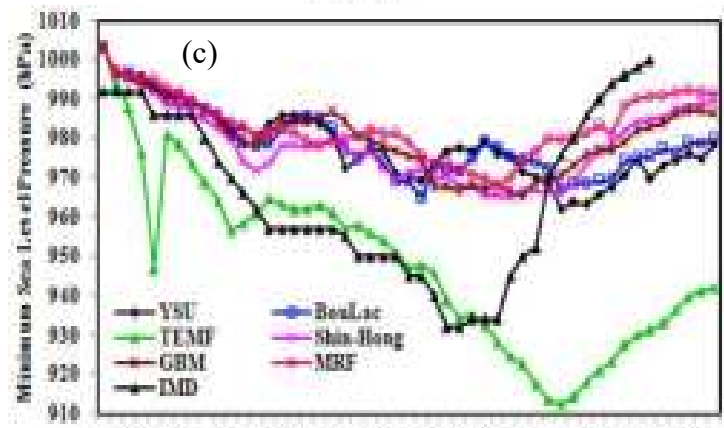

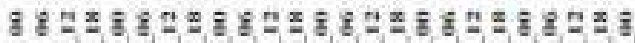

A 2 A A F Time(uic)
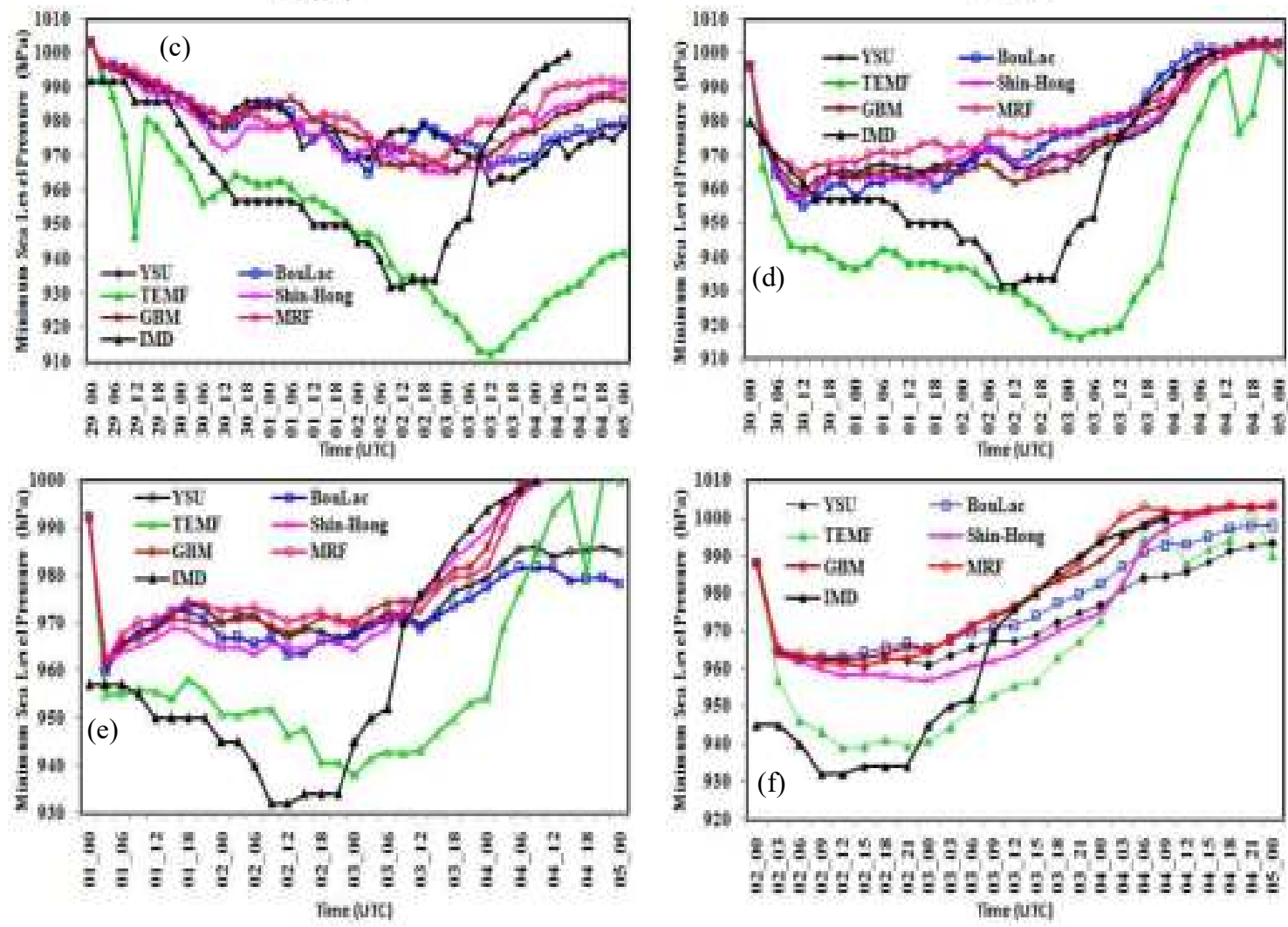

8 8.

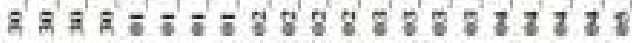
Iimt(unc)

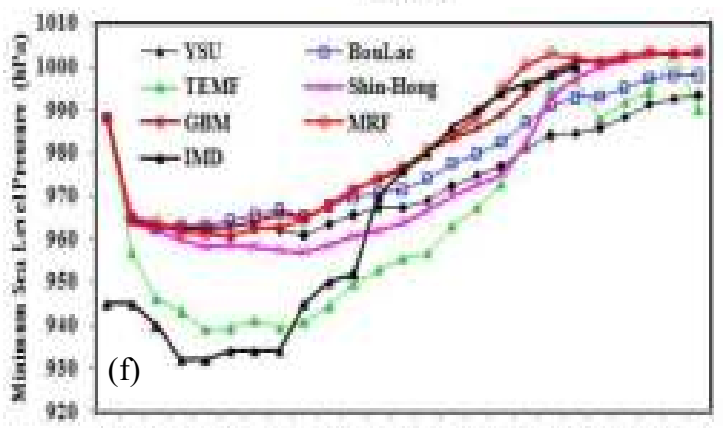

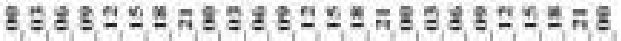

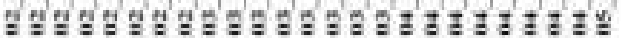
Timenaric)

Figure 2: Time variation of IMD observed and simulated ECP for the ICs at 0000 UTC of (a-d) 27 - 30 April and (e-f) $01-02$ May 2019, respectively for the GFS data of $1^{\circ}$ for six different PBL schemes.

\subsection{Maximum Wind Speed (MWS) at 10m height}

Time variation of IMD observed and simulated MWS at $10 \mathrm{~m}$ height by six different PBL schemes for the ICs at 0000 UTC of 27, 28, 29, 30 April, and 01 May and 02 May 2019 GFS data of $1^{\circ}$ are presented in Figures 3(a-f), respectively. It is seen from Figures 3(a-f) that MRF scheme has simulated lowest MWSICs on 27 and 28 April and TEMF scheme has simulated highest MWS at $10 \mathrm{~m}$ height for all the ICs. The MWS at $10 \mathrm{~m}$ height simulated by the TEMF scheme is higher than that of the observed MWS and almost similar for the ICs of 1st and 2nd May up to 0000 UTC of 3rd May. During the intensification period YSU, BouLac, Shin-Hong and GBM schemes have simulated much lower MWS than that of observed but after the landfall of TC Fani, all PBL schemes simulated much higher MWS than that of observed. On 30 April initial conditions the distribution pattern of simulated MWS after landfall is almost similar to that observed.

The simulated MWS for $1^{\circ}$ GFS data at the time (1500 UTC of 2nd May) of observed MWS ( $59 \mathrm{~m} / \mathrm{s}$ ) were 45 , $47,42,43,38$ and $41 \mathrm{~m} / \mathrm{s} ; 47,45,47,42,48$ and $42 \mathrm{~m} / \mathrm{s} ; 61,65,62,66,56$ and $62 \mathrm{~m} / \mathrm{s} ; 45,40,41,41,45$ and 42 $\mathrm{m} / \mathrm{s} ; 39,40,40,44,42$ and $40 \mathrm{~m} / \mathrm{s} ; 24,36,33,43,39$ and $44 \mathrm{~m} / \mathrm{s}$ for the ICs at 0000 UTC of 27, 28, 29, 30 April, and 01 May and 02 May 2019 for YSU, BouLac, TEMF, Shin-Hong, GBM and MRF PBL schemes, 
respectively. It is clearly seen that the MWS by TEMF scheme is almost similar to that of the observed MWS at $10 \mathrm{~m}$ height and all other schemes simulated much lower MWS.

The simulated MWS for $0.25^{\circ} \mathrm{GFS}$ data at the time (1500 UTC of 2nd May) of observed MWS (59 m/s) were $43,45,42,45,44$ and $42 \mathrm{~m} / \mathrm{s} ; 44,48,43,47,45$ and $43 \mathrm{~m} / \mathrm{s} ; 67,61,64,61,60$ and $61 \mathrm{~m} / \mathrm{s} ; 44,47,47,42,47$ and $46 \mathrm{~m} / \mathrm{s} ; 47,40,40,36,47,40$ and $43 \mathrm{~m} / \mathrm{s} ; 29,31,36,41,36$ and $41 \mathrm{~m} / \mathrm{s}$ for the ICs at 0000 UTC of 27, 28, 29, 30 April, and 01 May and 02 May 2019 for YSU, BouLac, TEMF, Shin-Hong, GBM and MRF PBL schemes, respectively. It is clearly seen that the MWS by TEMF scheme is almost similar to that of the observed MWS at $10 \mathrm{~m}$ height and all other schemes simulated much lower MWS. The simulated MWS for $1^{\circ}$ and $0.25^{\circ}$ GFS data are almost similar at the time of observed MWS.
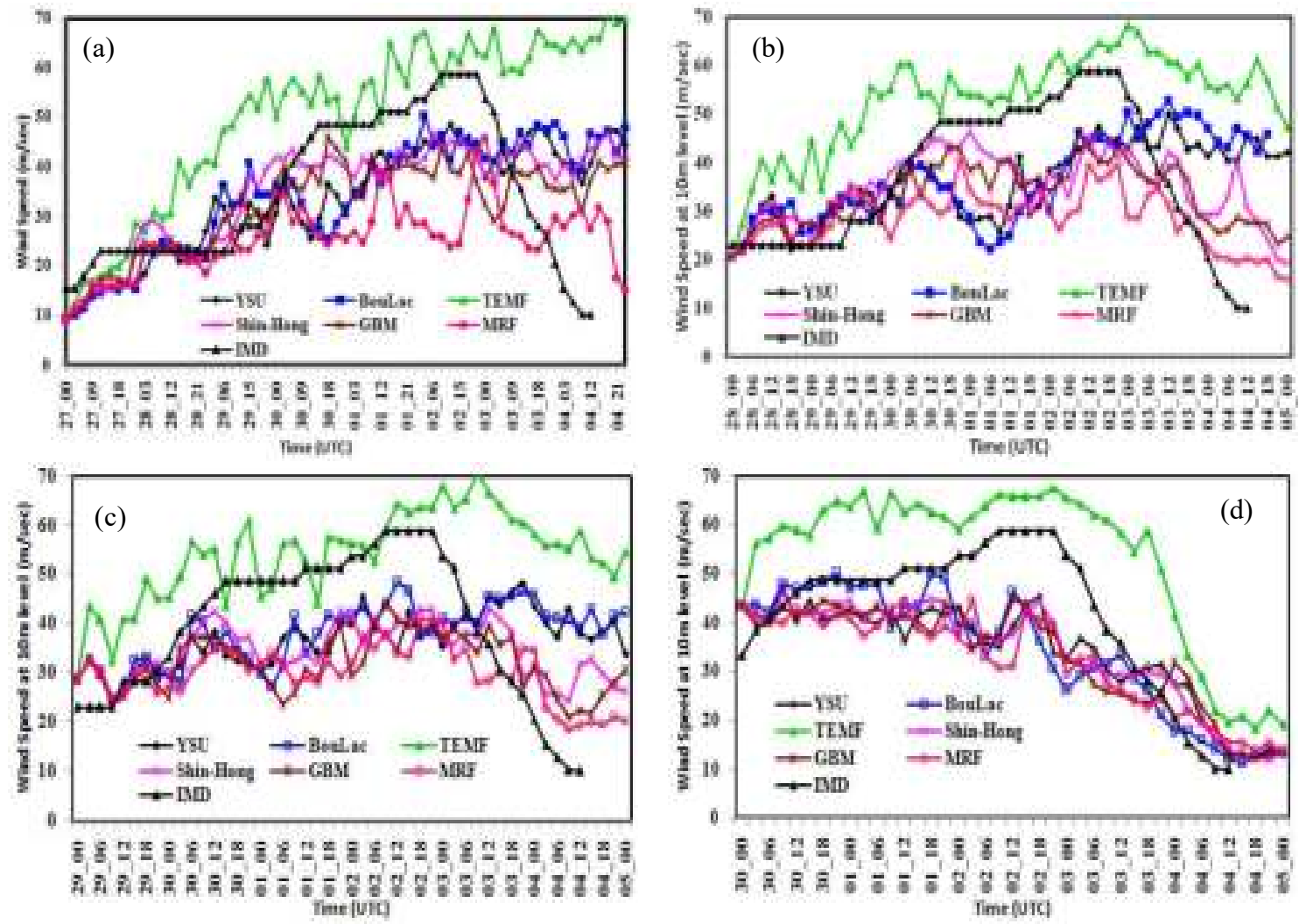

8 g

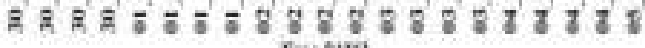
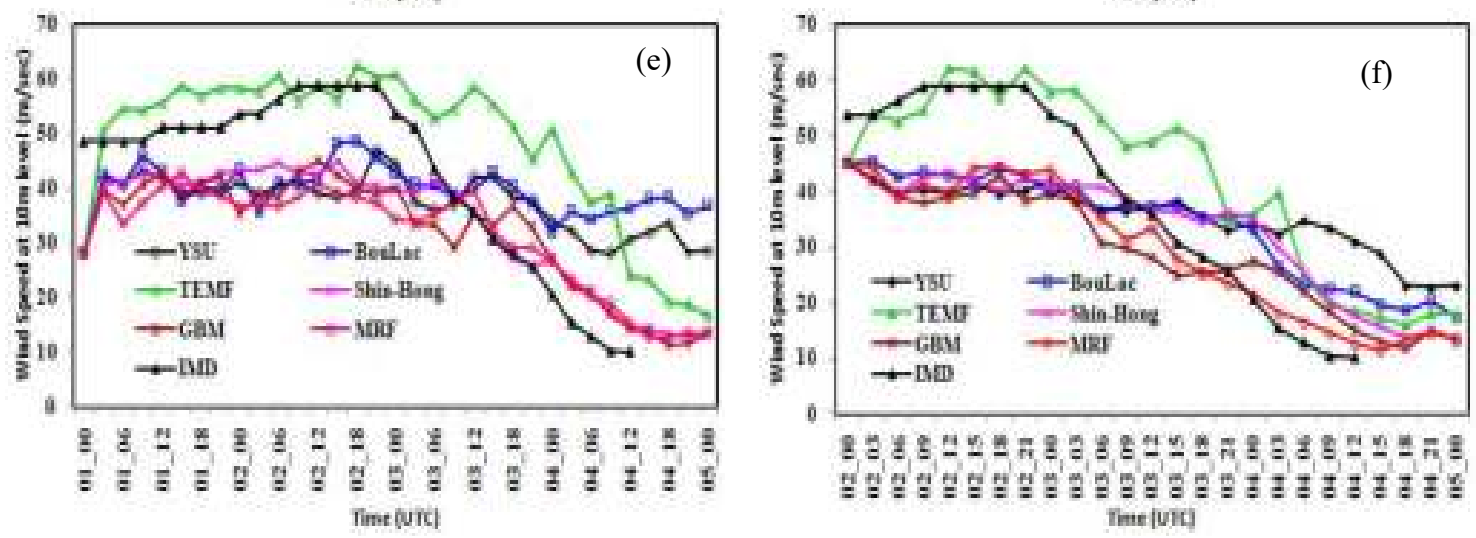

Figure 3: Time variation of IMD observed and simulated MWS $\left(\mathrm{m} \mathrm{s}^{-1}\right)$ at $10 \mathrm{~m}$ height for the ICs at 0000 UTC of (a-d) 27 - 30 April and (e-f) $01-02$ May 2019, respectively for the 2019 GFS data of $1^{\circ}$ for six different PBL schemes.

Except TEMF all other schemes have simulated higher MWS at other times but much lower than that of observed MWS. The differences of simulated MWS for $1^{\circ}$ and $0.25^{\circ}$ GFS data of different PBL schemes are not significant but zigzag for ICs on 27, 28 and 29 April. But the differences are significant and $0.25^{\circ}$ GFS data simulated much lower wind speed than that of $1^{\circ}$ GFS data after the landfall of TC Fani. Only 30 April initial 
conditions for all PBL schemes the simulated TC Fani crossed the land but for other ICs it would not cross the land that why after crossing land the simulated MWS are much higher than that of observed wind for all PBL schemes.

\subsection{Track of Tropical Cyclone Fani}

The 120-h simulated and IMD observed tracks of TC Fani for different PBL schemes for the GFS data of $0.25^{\circ}$ and $1^{\circ}$ and the ICs at 0000 UTC of 30 April are displayed in Figures 4(a-b). It is noted that roughly up to the landfall time (i.e., landfall during 0230 - 0430 UTC of 03 May 2019), the track forecast for different sensitivity experiments have shown reasonably accurate prediction. The northwards movement of the cyclonic storm Fani is well captured by the model simulations using the ICs of 30 April. The sensitivity test has revealed significant variance in track among the different PBL schemes for the GFS data of $0.25^{\circ}$ and $1^{\circ}$ resolution.

The TEMF scheme has simulated the most deviated track for the GFS data of $0.25^{\circ}$ and $1^{\circ}$ but MRF and GBM schemes have simulated less deviated track for the GFS data of $0.25^{\circ}$ and $1^{\circ}$ respectively for the ICs of 30 April 2019. The simulated track for all PBL schemes is moved parallel to the observed track up to the landfall time. Out of all PBL schemes the GBM scheme simulated track at the crossing point of TC Fani. The TC Fani crossed Odisha coast of India between 0230 - 0430 UTC of 3rd May 2019. The model simulated landfall time were 0600, 0300, 0300, 0600, 0600 and 1200 UTC of 3rd May 2019 for YSU, BouLac, TEMF, Shin-Hong, GBM and MRF schemes, respectively for the ICs of 30 April 2019 by $1^{\circ}$ GFS data. There is no time delay of landfall of TC Fani by BouLac and TEMF schemes for $1^{0}$ GFS data. The landfall time has delayed maximum 2-h by using ICs at 0000 UTC 30 April for YSU, Shin-Hong and GBM schemes and 8-h for MRF schemes. The landfall times were 0600, 1200, 0900, 0300, 0600 and 0600 UTC of 3rd May 2019 for YSU, BouLac, TEMF, ShinHong, GBM and MRF schemes, respectively for the ICs of 30 April 2019 by $0.25^{\circ}$ GFS data. There is no time delay of the landfall of TC Fani for the Shin-Hong scheme by $0.25^{\circ}$ GFS data. The landfall time has been delayed by maximum 2-h for using ICs at 0000 UTC 30 April for YSU, GBM and MRF schemes, by 5-h for TEMF and by 8 -h for BouLac scheme, respectively.
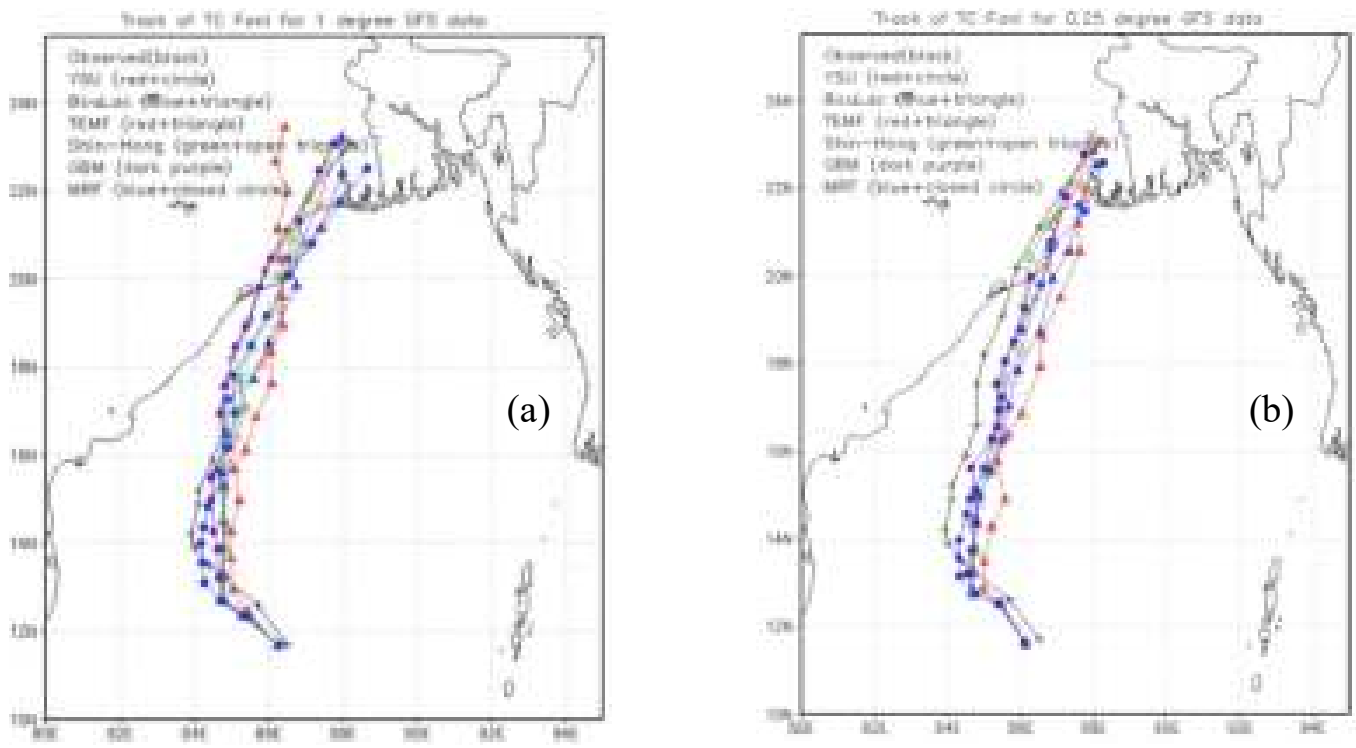

Figure 4: Model simulated and IMD Observed tracks of TC 'Fani' using six different PBL schemes with (a) $0.25^{\circ}$ and (b) $1^{0}$ GFS data for the ICs at 0000 UTC of 30 April.

\subsection{Error on Track and Intensity of TC Fani}

The track error has been calculated for the GFS data of $1^{\circ}$ and $0.25^{\circ}$ with the ICs at 0000 UTC of 30 April 2019 on the basis of the IMD observed track and are presented in Figures 5(a-b). It was found that at the starting of the model simulation i.e. with the ICs on 30 April the center of the cyclone was identified almost $27 \mathrm{~km}$ farther from the observational points. This error may come for the difficulties of finding the centre at the initial stage. The error was systematic for all PBL schemes for the ICs at 0000 UTC of 30 April at $0.25^{\circ}$ and $1^{\circ}$ GFS data but the track error was much less for $1^{0}$ GFS data than that of $0.25^{0}$ GFS data. The TEMF scheme has simulated the most deviated track and MRF scheme has simulated less deviated track for all through the simulation. 

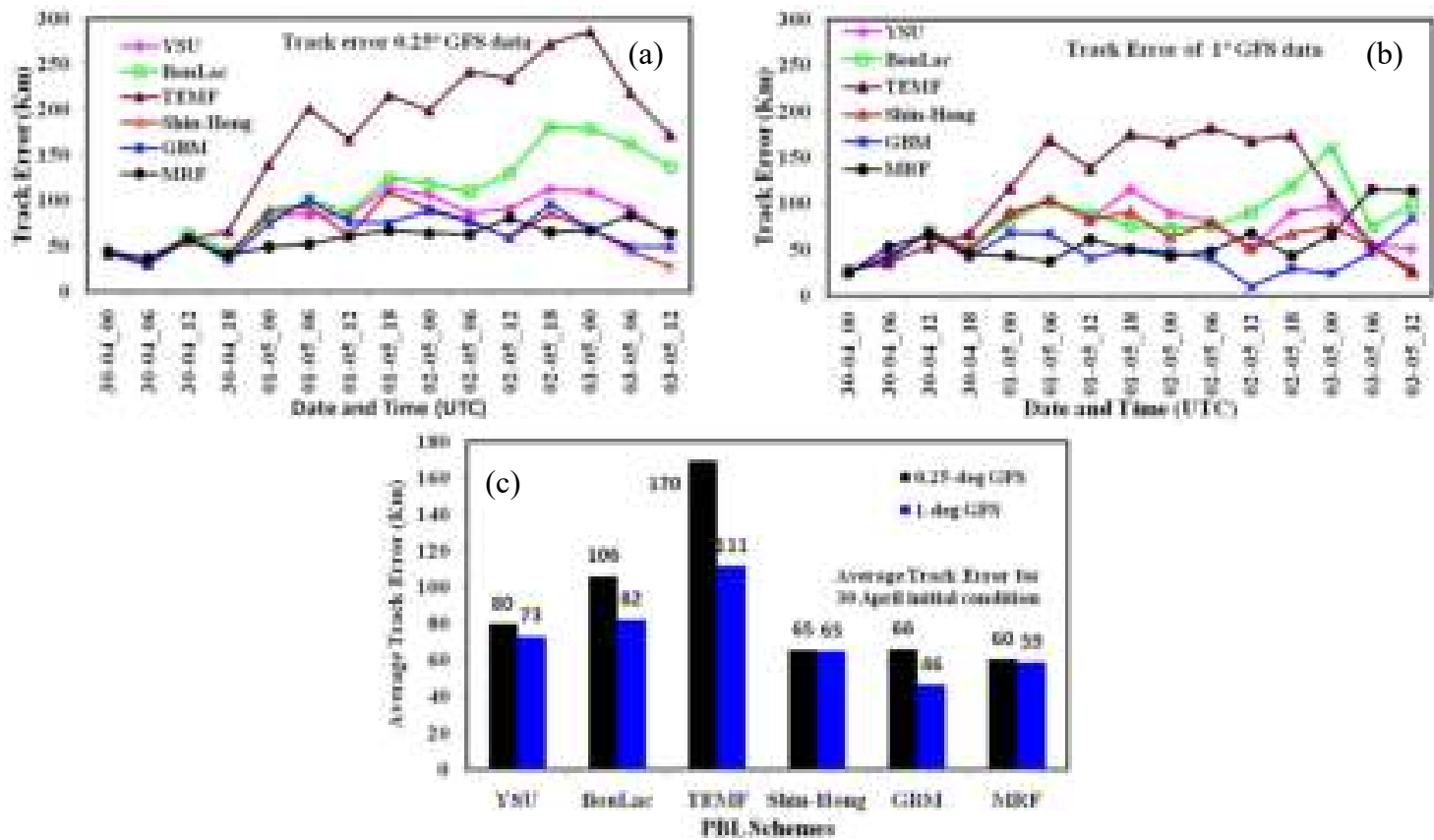

Figure 5: Simulated Track Error of TC Fani from IMD observed track for all PBL schemes in combination with (a) $0.25^{\circ} \mathrm{GFS}$ data, (b) $1^{\circ} \mathrm{GFS}$ data and (c) average track error for $0.25^{\circ}$ and $1^{\circ} \mathrm{GFS}$ data with the ICs at $0000 \mathrm{UTC}$ of 30 April 2019.
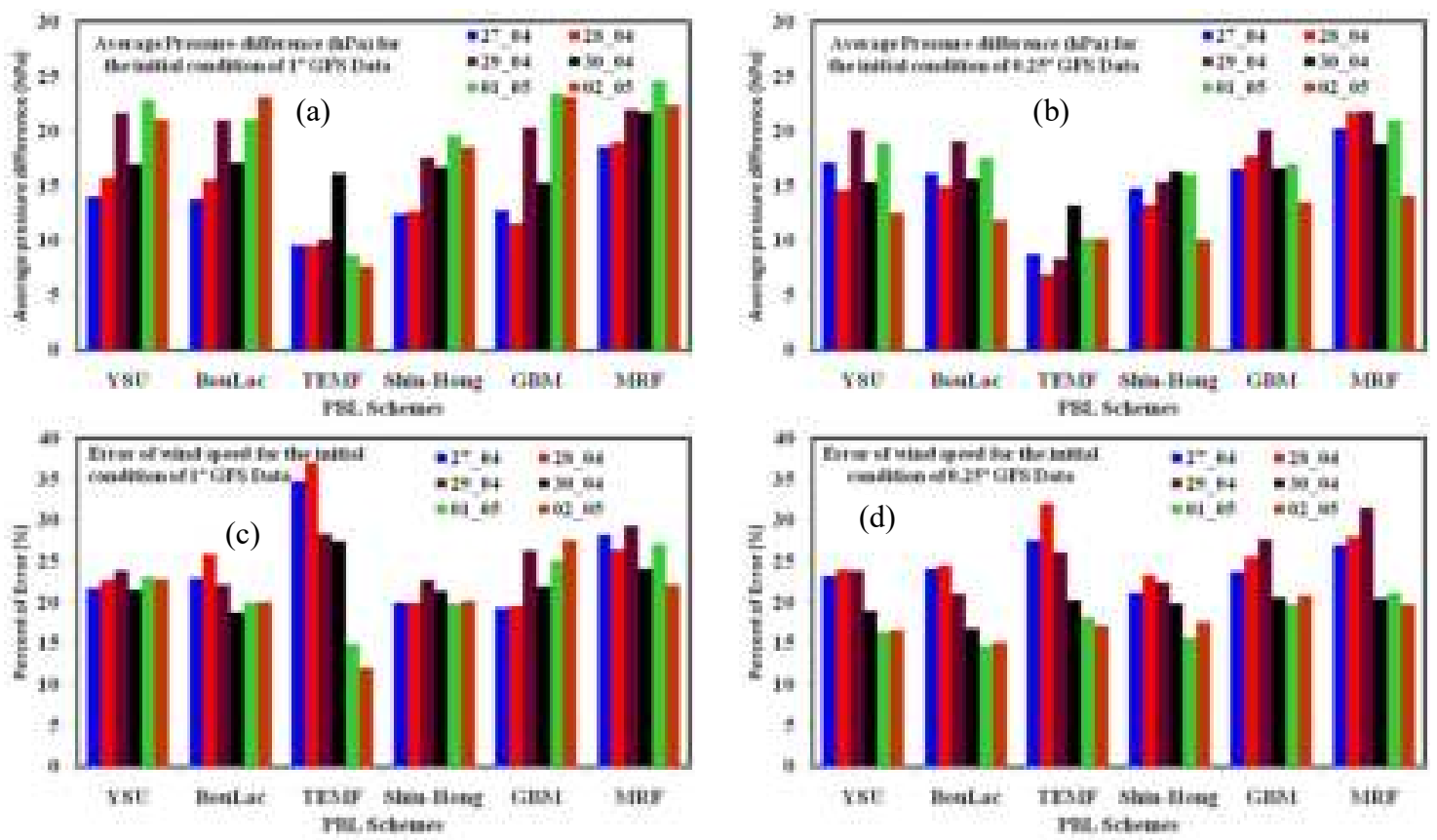

Figure 6: Simulated average ECP difference for (a) $1^{\circ}$ and (b) $0.25^{\circ}$ GFS data and differences of average MSW speed at $10 \mathrm{~m}$ height for (c) $1^{\circ}$ and (d) $0.25^{\circ}$ GFS data for the ICs at 27, 28, 29, 30 April and 1st and 2nd May for YSU, BouLac, TEMF, Shin-Hong, GBM and MRF schemes.

At the time of landfall Shin-Hong PBL scheme has simulated minimum track error for $1^{\circ}$ and $0.25^{\circ}$ GFS data and TEMF scheme for $1^{\circ}$ GFS data with the initial condition at 0000 UTC of 30 April. The average track errors (Figure 5c) are comparable for $1^{\circ}$ and $0.25^{\circ}$ GFS data of Shin-Hong, GBM and MRF scheme with the ICs at $0000 \mathrm{UTC}$ as of 30 April. From the figure it is seen that $0.25^{\circ} \mathrm{GFS}$ data has simulated higher track error than that of $1^{\circ}$ GFS data for all studied PBL schemes. Among the PBL schemes, the TEMF scheme has simulated much higher average track error and the GBM scheme has simulated lower average track error. The average track error for $1^{\circ}$ GFS data are 73, 82, 111, 6546 and $59 \mathrm{~km}$ and for $0.25^{\circ}$ GFS data it was 80, 106, 170, 65, 66 and $60 \mathrm{~km}$ for YSU, BouLac, TEFM, Shin-Hong, GBM and MRF schemes, respectively. 
The average ECP difference is found minimum for TEMF scheme for $1^{\circ}$ and $0.25^{\circ}$ GFS data [Figures 6(a-b)] and maximum for MRF scheme for all the ICs of model run. The average minimum ECP differences are 10, 10, 10,9 and $8 \mathrm{hPa}$ for TEMF scheme and maximum 19, 19, 22, 22, 25 and $22 \mathrm{hPa}$ for MRF scheme with the ICs at 27, 28, 29, 30 April and 1st and 2nd May respectively. The TEMF scheme has simulated maximum and minimum difference of average MSW at $10 \mathrm{~m}$ level for $1^{\circ} \mathrm{GFS}$ data [Figures 4(c-d)] for different ICs of model run. The errors of MSW at $10 \mathrm{~m}$ height for $1^{\circ}$ GFS data are found 35, 37, 28, 27, 15 and $12 \%$ for the TEMF scheme with the ICs at 27, 28, 29, 30 April and 1st and 2nd May respectively.

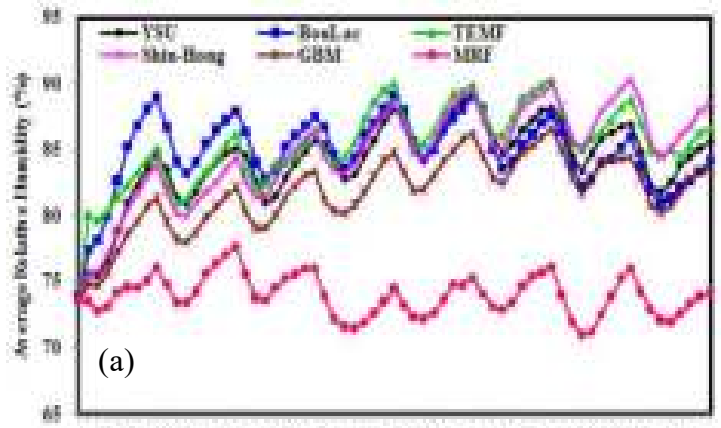

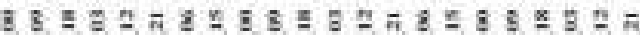

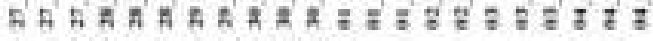
Timentuse

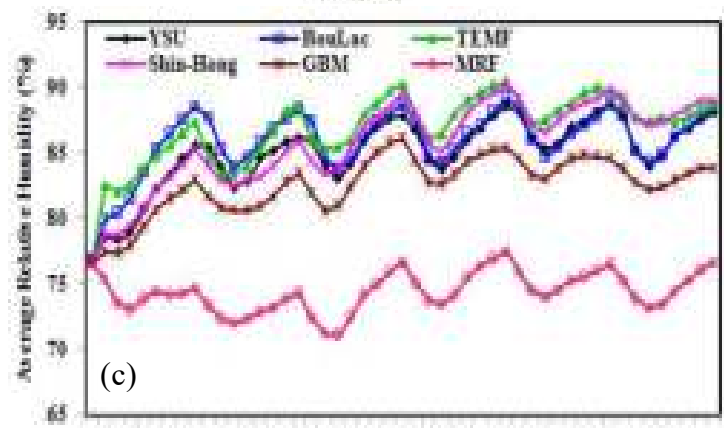

B

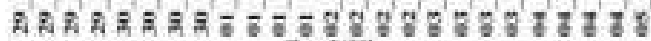
Time(vic)

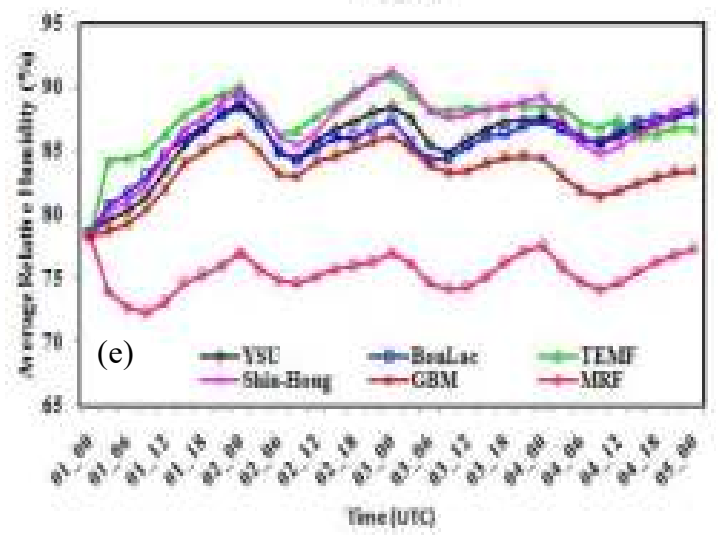

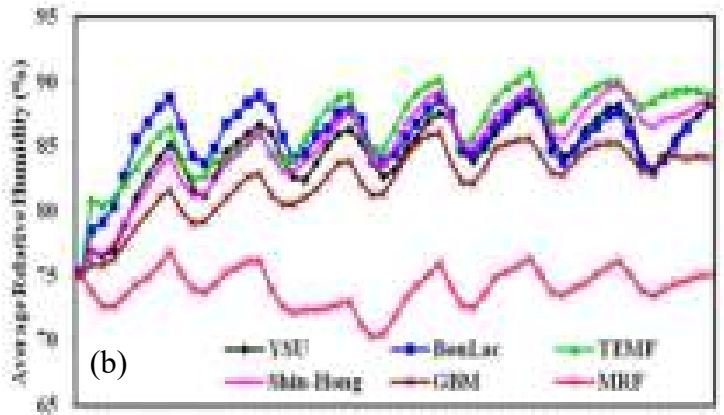

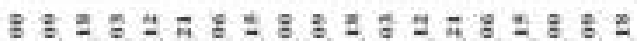

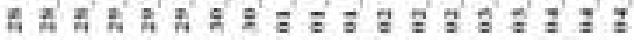
Timeluto

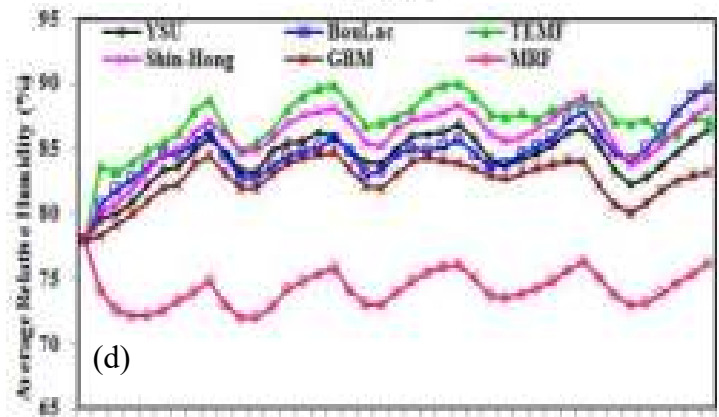

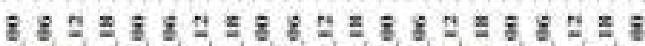

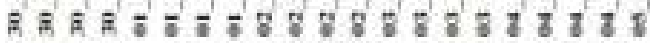
Time(UTi)

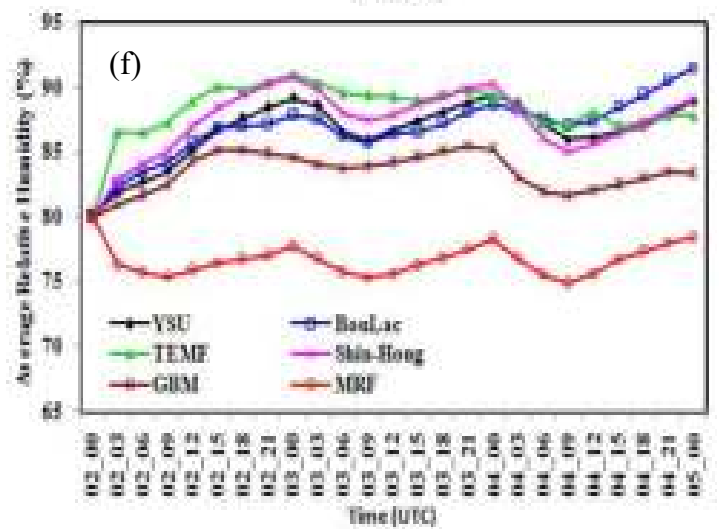

Figure 7: Time variation of simulated area averaged RH (\%) at $2 \mathrm{~m}$ height for the ICs at 0000 UTC of (a-d) $27-$ 30 April and (e-f) $01-02$ May 2019, respectively for the GFS data of $1^{\circ}$ for six different PBL schemes.

\subsection{Area averaged Relative Humidity $(\mathrm{RH})$ at $\mathbf{2 m}$ height}

The area averaged simulated RH for six different PBL schemes for the ICs at 0000 UTC of 27, 28, 29, 30 April, and 01 May and 02 May 2019 GFS data of $1^{\circ}$ is presented in Figures 7(a-f), respectively. From the figures it is found that the area averaged RH simulated maximum at $0000 \mathrm{UTC}$ and minimum at $0900 \mathrm{UTC}$ every day for all PBL schemes. The pattern is oscillatory and its time period is almost constant. The distribution pattern of model simulated RH is almost similar for $1^{\circ}$ and $0.25^{\circ}$ GFS data for all the studied PBL schemes. In Figures 7(a-f), 
MRF scheme has simulated lowest area averaged RH and TEMF scheme has simulated highest area averaged $\mathrm{RH}$ at $2 \mathrm{~m}$ height for all the ICs.

The significant variation of area averaged RH is simulated during day and night by all PBL schemes for 27, 28 and 29 April ICs. But overall the maximum and minimum values of area averaged RH does not change during period of formation and dissipation of TC Fani in the BoB. The amplitude of oscillation of area averaged RH is decreased as the initial condition of model run proceeds forward. The differences of area averaged RH are insignificant at day and night for the ICs of 1st and 2nd May. The area averaged simulated RH is found TEMF $>$ Shin-Hong $>$ YSU $>$ BouLac $>$ GBM $>$ MRF schemes almost although the simulation time except little anomalies.

The differences of simulated area averaged RH for $1^{\circ}$ and $0.25^{\circ}$ GFS data of different PBL schemes is significant for 27, 28 and 29 April ICs. The differences of simulated RH for all PBL schemes are also oscillatory during above mentioned period. The simulated RH by $1^{\circ}$ output is always positive for YSU and BouLac schemes for all ICs. The simulated RH for other PBL schemes by $1^{0}$ output is lower than that of $0.25^{\circ}$ data output initially during night time and positive after three days of simulation with the initial condition of 27 and 28 April. Only 30 April initial condition for all PBL schemes the simulated TC Fani crossed the land but for other ICs it would not cross the land. For ICs on 30 April, 1 May and 2 May, the differences of simulated RH are oscillatory up to 0600 UTC of 3 May. After that the distribution pattern of RH is flattened.

The area averaged maximum RH has simulated $89,89,90,90,87$ and $78 \%$ for $1^{\circ}$ GFS data and $87,88,90,90$, 86 and $79 \%$ for $0.25^{\circ}$ GFS data by YSU, BouLac, TEMF, Shin-Hong, GBM and MRF PBL schemes, respectively for the ICs of 27 April. The area averaged values of minimum $\mathrm{RH}$ are 74, 74, 74, 74, 74 and $71 \%$ for $1^{\circ} \mathrm{GFS}$ data and $74,74,74,74,73$ and $69 \%$ for $0.25^{\circ}$ GFS data as simulated by YSU, BouLac, TEMF, ShinHong, GBM and MRF schemes, respectively for the ICs of 27 April. The area and time averaged values of RH are $84,85,85,85,82$ and $74 \%$ for $1^{\circ}$ GFS data and $82,83,84,84,81$ and $73 \%$ for $0.25^{\circ}$ GFS data by YSU, BouLac, TEMF, Shin-Hong, GBM and MRF PBL schemes, respectively for the ICs of 27 April.

\subsection{Area averaged Temperature at $2 \mathrm{~m}$ height}

The area averaged model simulated temperature at $2 \mathrm{~m}$ height by six different PBL schemes for the ICs at 0000 UTC of 27, 28, 29, 30 April, and 01 May and 02 May 2019 GFS data of $1^{0}$ is presented in Figures 8(a-f) respectively. From the figures it is found that the simulated area averaged temperature at $2 \mathrm{~m}$ height is found maximum at $0900 \mathrm{UTC}$ and minimum at $0000 \mathrm{UTC}$ every day for all PBL schemes. This indicates that at which time the $\mathrm{RH}$ at $2 \mathrm{~m}$ height is simulated minimum (maximum) the average temperature is found to be maximum (minimum) at that time. The crest (trough) of temperature oscillation is matched with the trough (crest) of RH and vice versa. The pattern is oscillatory and its time period is almost constant. The distribution pattern of model simulated area averaged temperature at $2 \mathrm{~m}$ height is almost similar for $1^{0}$ [Figures $8(\mathrm{a}-\mathrm{f})$ ] and $0.25^{\circ}$ (Figures not shown) GFS data for all the studied PBL schemes except TEMF scheme.

The crest of temperature is found to be decreased and the trough of temperature is found to be increased with the progression of simulation time for the ICs of 27 and 28 April for all PBL schemes for $1^{\circ}$ [Figures 8(a-b)] and $0.25^{\circ}$ (Figure not shown) GFS data. For other ICs, the crest of temperature is found to be decreased but the trough of temperature is almost constant with the progression of time. In Figures 8(a-f), the TEMF scheme has simulated significantly higher area averaged temperature at $2 \mathrm{~m}$ height than that of other schemes for all the ICs of model run. It is also seen that the crest of temperature for the TEMF scheme is decreased continuously for all the ICs with the progression of simulation time except little anomalies. The simulated temperature is found maximum and at the crest its values around $58^{\circ} \mathrm{C}$ for $1^{\circ}$ (Figure $8 \mathrm{a}$ ) and $0.25^{\circ}$ (Figure not shown) GFS data.

This indicates that initially the simulated temperature at $2 \mathrm{~m}$ height was much higher than that of sea surface temperature (SST). The amplitude of simulated temperature for other PBL schemes is almost constant from the initial time of simulation to the landfall of TC Fani in the BoB. Their differences are insignificant except the TEMF scheme. It is also seen that the simulated ECP is higher and MWS at 10m height is much lower than that observed for all PBL schemes except the TEMF scheme. That means simulated ECP and MWS is related to the simulated temperature at $2 \mathrm{~m}$ height. The TEMF scheme has simulated much higher temperature at $2 \mathrm{~m}$ height and also lower ECP and higher MWS at $10 \mathrm{~m}$ height. The simulated ECP and MWS at 10m height by TEMF scheme are almost similar to that observed. The temperature at $2 \mathrm{~m}$ height is positively correlated with the ECP and MWS at $10 \mathrm{~m}$ height.

YSU, BouLac, Shin-Hong, GBM and MRF schemes have simulated maximum temperature around $46^{\circ} \mathrm{C}$ at the crest point which is found at afternoon (0300 UTC) for the ICs of 27 and 28 April 2019 for $1^{\circ}$ and $0.25^{\circ}$ GFS data. The amplitude of temperature is decreased continuously at the crest point with the progression of initial condition of model run. All PBL schemes have simulated minimum temperature around $31^{\circ} \mathrm{C}$ at trough which is 
found in the morning (0000 UTC). The $1^{\circ} \mathrm{GFS}$ data has simulated almost all through the time higher temperature than that of $0.25^{\circ} \mathrm{GFS}$ data of model run for all the ICs for all PBL schemes.
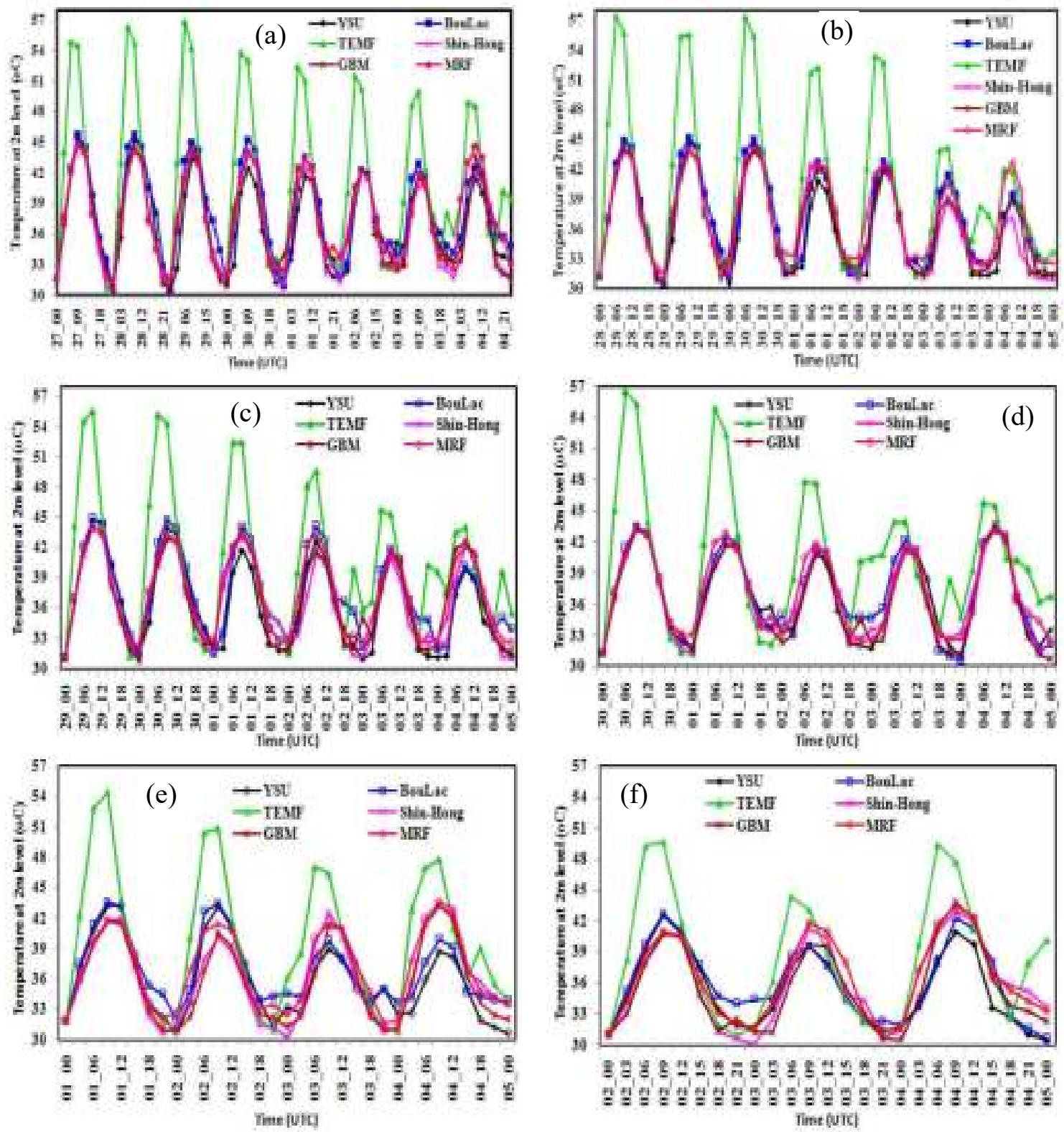

Figure 8: Time variation of simulated area averaged temperature $\left({ }^{\circ} \mathrm{C}\right)$ at $2 \mathrm{~m}$ height for the ICs at 0000 UTC of (a-d) 27 - 30 April and (e-f) 01 - 02 May 2019, respectively for the GFS data of $1^{0}$ for six different PBL schemes.

\subsection{Average Potential Temperature at $2 \mathrm{~m}$ height}

The area averaged model simulated potential temperature at $2 \mathrm{~m}$ height by six different PBL schemes for the ICs at 0000 UTC of 27, 28, 29, 30 April, and 01 May and 02 May 2019 GFS data of $1^{0}$ GFS data is presented in Figures $9(\mathrm{a}-\mathrm{f})$, respectively. From the figures, it is found that the simulated area averaged potential temperature at $2 \mathrm{~m}$ height is found maximum at $0900 \mathrm{UTC}$ and minimum at $0000 \mathrm{UTC}$ every day for all PBL schemes. This indicates that at which time the temperature at $2 \mathrm{~m}$ height is simulated maximum (minimum) the potential temperature is also found to be maximum (minimum) at that time. The crest (trough) of potential temperature oscillation is matched with the crest (trough) of temperature at $2 \mathrm{~m}$ height. The pattern is oscillatory and its time period is almost constant. The distribution pattern of model simulated area averaged potential temperature at $2 \mathrm{~m}$ height is almost similar for $1^{\circ}$ [Figures $\left.9(\mathrm{a}-\mathrm{f})\right]$ and $0.25^{\circ}$ (Figure not shown) GFS data for all the studied PBL schemes except the TEMF scheme. 
The crest of potential temperature is found to be decreased and the trough of potential temperature is found to be increased with the progression of simulation time for the ICs of 27 and 28 April for all PBL schemes for $1^{0}$ [Figures $9(a-b)]$ and $0.25^{\circ}$ GFS data of model run. For other ICs, the crest of potential temperature is found to be decreased but the trough of potential temperature is almost constant with the progression of time. In Figures 9(af), the TEMF scheme has simulated significantly higher area averaged potential temperature at $2 \mathrm{~m}$ height than that of other schemes for all the ICs of model run.
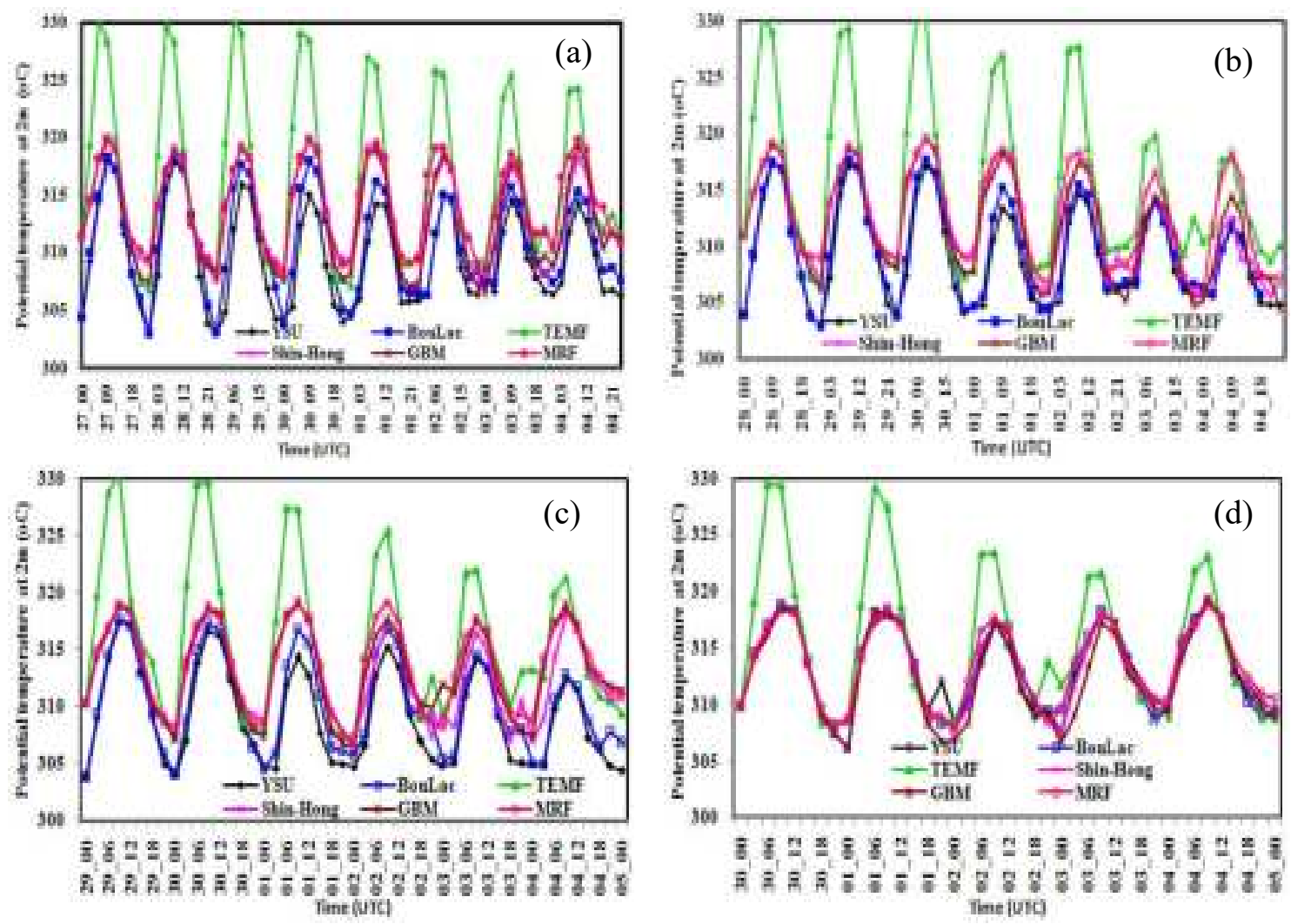

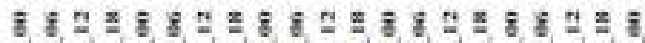
तै हो
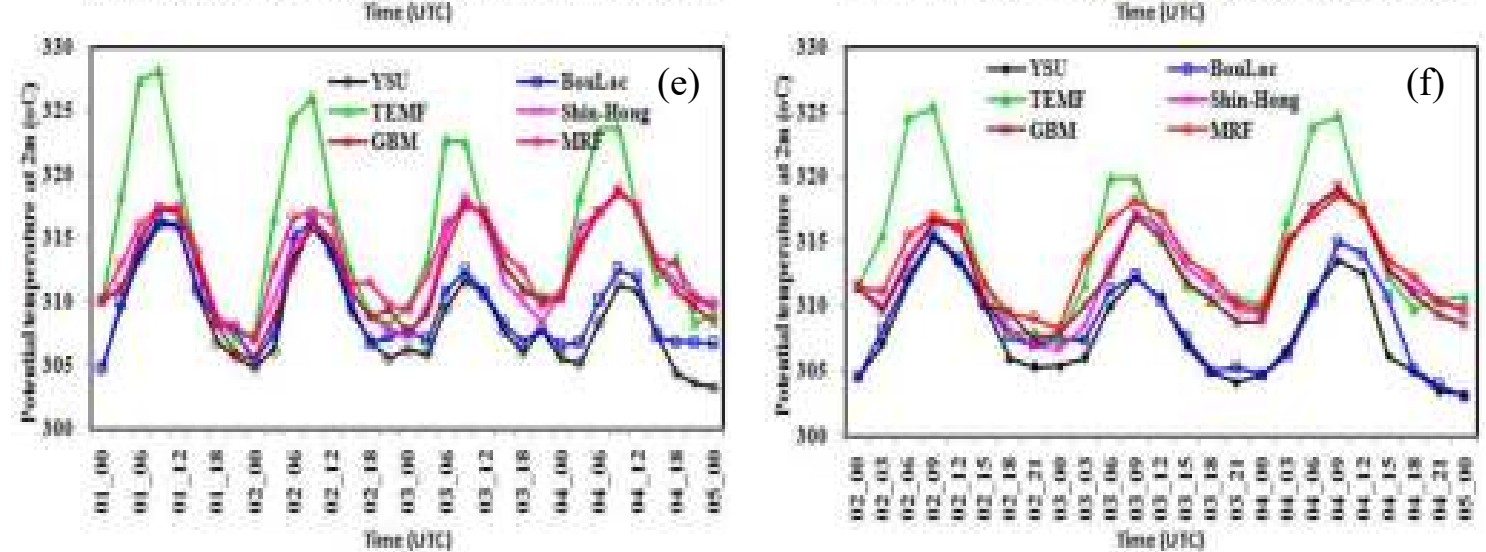

Figure 9: Time variation of simulated average potential temperature $\left({ }^{\circ} \mathrm{K}\right)$ at $2 \mathrm{~m}$ height for the ICs at 0000 UTC of (a-d) 27 - 30 April and (e-f) 01 - 02 May 2019, respectively for the GFS data of $1^{0}$ for six different PBL schemes.

It is also seen that the crest of potential temperature for TEMF scheme is decreased continuously for all the ICs with the progression of simulation time except little anomalies. The simulated potential temperature is found maximum and at the crest its values around $330 \mathrm{~K}$ for $1^{\circ}$ (Figure 9a) and $0.25^{\circ} \mathrm{GFS}$ data. This indicates that initially the simulated potential temperature at $2 \mathrm{~m}$ height is much higher than that of the potential temperature at the sea surface. The amplitude of simulated potential temperature for other PBL schemes is almost constant from the initial time of simulation to the landfall of TC Fani in the BoB. Their differences are insignificant except for the TEMF scheme. It is also seen that the simulated ECP is higher and MWS at 10m height is much lower than that observed for all PBL schemes except the TEMF scheme. That means simulated ECP and MWS 
is related to the simulated potential temperature at $2 \mathrm{~m}$ height. The potential temperature at $2 \mathrm{~m}$ height is positively correlated with the ECP, MWS at $10 \mathrm{~m}$ height and temperature at $2 \mathrm{~m}$ height. YSU, BouLac, ShinHong, GBM and MRF schemes have simulated maximum potential temperature around $318 \mathrm{~K}$ at the crest point which is found at afternoon (0300 UTC) for the ICs of 27 and 28 April 2019 for $1^{\circ}$ and $0.25^{\circ}$ GFS data. The amplitude of potential temperature is decreased continuously at the crest point with the progression of initial condition of model run. All PBL schemes have simulated minimum potential temperature around $304 \mathrm{~K}$ at trough which is found in the morning (0000 UTC). The $1^{\circ} \mathrm{GFS}$ data has simulated almost all through the time higher potential temperature than that of $0.25^{\circ} \mathrm{GFS}$ data of model run for all the ICs for TEMF, Shin-Hong, GBM and MRF schemes and YSU and BouLac schemes simulated lower potential temperature.
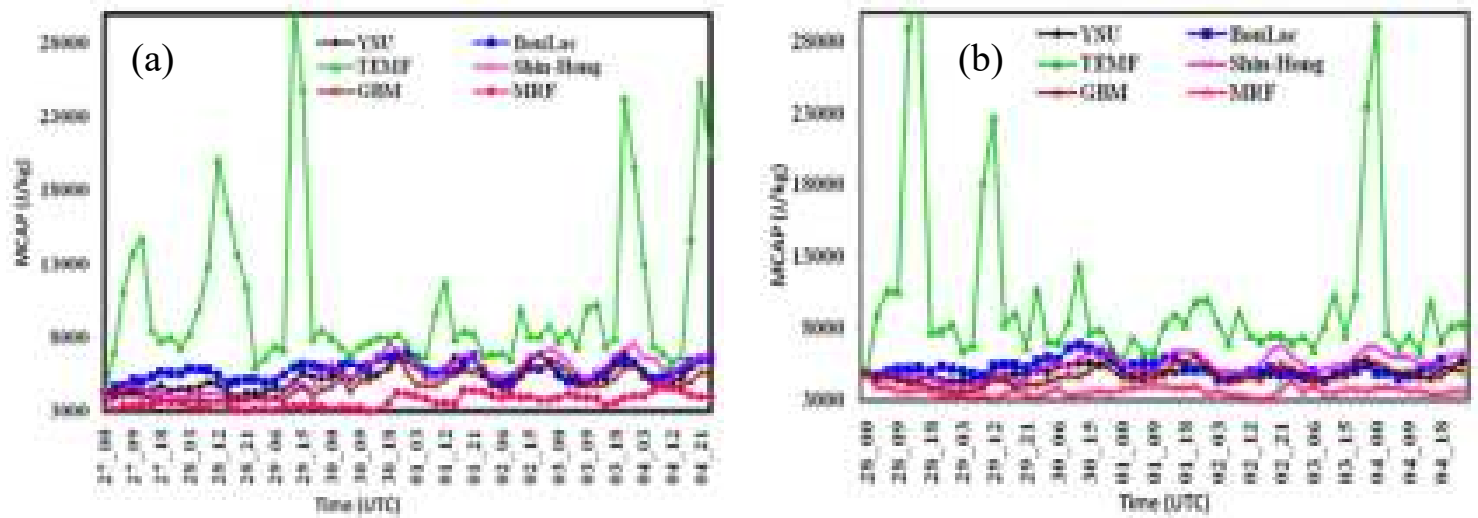

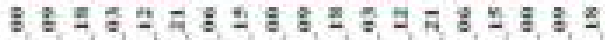

म Tine (utt)
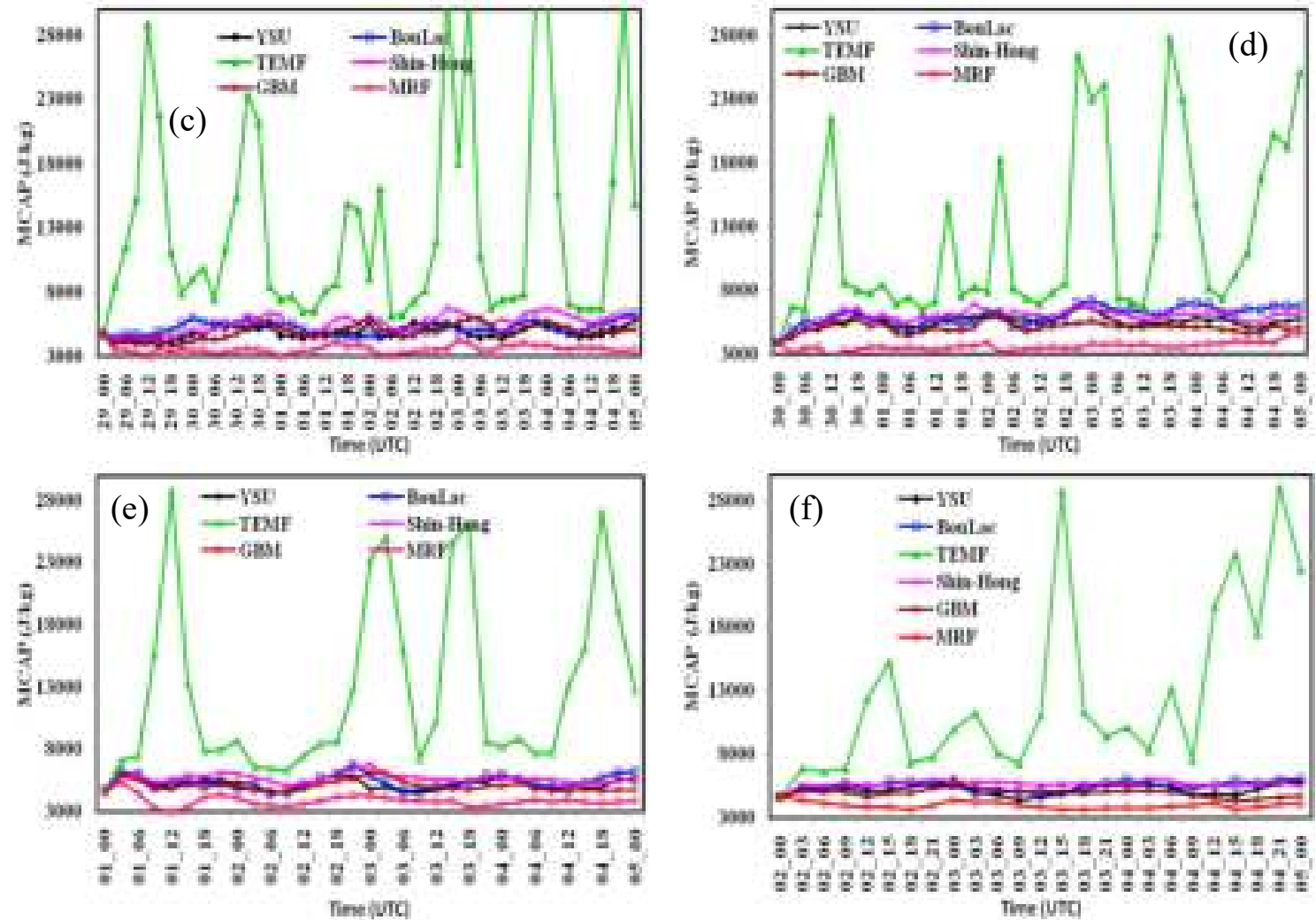

Figure 10: Time variation of simulated maximum convective available potential energy $(\mathrm{J} / \mathrm{kg})$ for the ICs at 0000 UTC of (a-d) 27 - 30 April and (e-f) $01-02$ May 2019, respectively for the GFS data of $1^{\circ}$ for six different PBL schemes.

\subsection{Modified Convective Available Potential Energy (MCAPE)}

CAPE is a measure of the amount of energy available for convection. It is directly related to the maximum potential vertical speed within an updraft and its higher values indicate greater potential for severe weather. The area averaged model simulated MCAP by six different PBL schemes for the ICs at 0000 UTC of 27, 28, 29, 30 
April, and 01 May and 02 May 2019 GFS data of $1^{\circ}$ is presented in Figures 10 (a-f), respectively. From the figures, it is found that the simulated area averaged MCAP has an oscillatory pattern but no regular trend. The distribution pattern of model simulated area averaged MCAP is almost similar for $1^{\circ}$ [Figures $10(\mathrm{a}-\mathrm{f})$ ] and $0.25^{\circ}$ GFS data for all the studied PBL schemes.

The simulated average MCAP for all PBL schemes is zigzag. The TEMF scheme has simulated significantly higher and MRF scheme has simulated lower area averaged MCAP than that of other schemes for all the ICs of model run. There is little difference of area averaged MCAP between $1^{\circ}$ and $0.25^{\circ}$ GFS data for all ICs by all PBL schemes but no trend. The area averaged maximum MCAP has simulated 6838, 6965, 30787, 7551, 6727 and $4403 \mathrm{~J} / \mathrm{kg}$ for $1^{\circ} \mathrm{GFS}$ data and $6786,7695,24740,7454,6617$ and $4436 \mathrm{~J} / \mathrm{kg}$ for GFS $0.25^{\circ}$ data by YSU, BouLac, TEMF, Shin-Hong, GBM and MRF PBL schemes, respectively for the initial condition of 27 April. The area averaged values of minimum MCAP are 3939, 4242, 4242, 3738, 3615 and $2878 \mathrm{~J} / \mathrm{kg}$ for $1^{\circ} \mathrm{GFS}$ data and $3789,4163,5543,3814,3732$ and $3044 \mathrm{~J} / \mathrm{kg}$ for $0.25^{\circ} \mathrm{GFS}$ data as simulated by YSU, BouLac, TEMF, Shin-Hong, GBM and MRF schemes, respectively for the initial condition of 27 April. The area and time averaged values of MCAP are 5174, 5609, 9620, 5279, 4692 and $3572 \mathrm{~J} / \mathrm{kg}$ for $1^{\circ}$ GFS data and 5119, 5620, $10187,5454,4888$ and $3616 \mathrm{~J} / \mathrm{kg}$ for $0.25^{\circ} \mathrm{GFS}$ data by YSU, BouLac, TEMF, Shin-Hong, GBM and MRF PBL schemes, respectively for the initial condition of 27 April. It is also found that the simulated maximum area and time averaged MCAP by TEMF scheme and minimum by MRF scheme all through the study period. The BouLac scheme has simulated the second maximum of area and time average MCAP and GBM scheme simulated second minimum.

\subsection{Average Planetary Boundary Layer (PBL) Height}

The PBL is the layer in the lower part of the troposphere with thickness ranging from a few hundred meters to a few kilometers within which the effects of the Earth's surface are felt by the atmosphere. The area averaged model simulated PBL height by six different PBL schemes for the ICs at 0000 UTC of 27, 28, 29, 30 April, and 01 May and 02 May 2019 GFS data of $1^{\circ}$ is presented in Figures 11(a-f), respectively. From the figures, it is found that the simulated area averaged PBL height is an oscillatory pattern. The distribution pattern of model simulated area averaged PBL height is almost similar for $1^{\circ}$ [Figures $11(\mathrm{a}-\mathrm{f})$ ] and $0.25^{\circ}$ (Figures not shown) GFS data for all the studied PBL schemes. From the figures, the simulated area averaged PBL height is found maximum at 0900-1200 UTC and minimum at 1500-0600 UTC every day for all PBL schemes except the TEMF scheme. Again, for the TEMF scheme the maximum area averaged PBL height is found during 09000000 UTC and minimum at 0300-0600 UTC.

The crest of PBL height is found to be decreased and the trough of PBL height is found to be increased with the progression of simulation time for the ICs of 27 and 28 April for all PBL schemes for $1^{0}$ [Figures 11(a-b)] and $0.25^{\circ} \mathrm{GFS}$ data. For other ICs the crest of PBL height is found to be decreased but the trough of PBL height is almost constant with the progression of time. In Figures 11(a-f), the crest is found during longer time at 09000000 UTC and trough is found for shorter time 0300-0600 UTC for TEMF scheme. Again, for YSU, BouLac, Shin-Hong, GBM and MRF schemes the crest is simulated for shorter time 0900-1200 UTC and trough is simulated for longer time 1500-0600 UTC.

The area averaged maximum PBL height has simulated 4338, 4147, 4596, 4309, 4117 and $4555 \mathrm{~m}$ for $1^{\circ} \mathrm{GFS}$ data and 4495, 4611, 4600, 4451, 4112 and $4613 \mathrm{~m}$ for $0.25^{\circ} \mathrm{GFS}$ data and minimum 1517, 1424, 1780, 1476, 1542 and $1336 \mathrm{~m}$ for $1^{\circ} \mathrm{GFS}$ data and $1465,1345,1785,1417,1085$ and $1368 \mathrm{~m}$ for $0.25^{\circ}$ GFS data by YSU, BouLac, TEMF, Shin-Hong, GBM and MRF PBL schemes, respectively for the initial condition of 30 April. The area and time averaged PBL heights are found 2662, 2878, 3583, 2703, 2577 and $2727 \mathrm{~m}$ for $1^{\circ}$ GFS data and 2861, 2838, 3633, 2779, 2772 and $2801 \mathrm{~m}$ for $0.25^{\circ}$ GFS data by YSU, BouLac, TEMF, Shin-Hong, GBM and MRF schemes, respectively for the initial condition of 30 April. It is also found that the simulated maximum area and time averaged PBL height by TEMF scheme and minimum by GBM scheme all through the study period. The BouLac scheme simulated the second maximum of area and time average PBL height and the ShinHong scheme simulated the second minimum. Although the amplitude at the crest position is almost similar for all PBL schemes but the PBL height for TEMF scheme is found maximum time at the crest position that's why the average height is much higher than the other schemes.

\subsection{Average High Cloud}

The area averaged simulated high cloud (\%) by six different PBL schemes for the ICs at 0000 UTC of 27, 28, 29, 30 April, and 01 and 02 May 2019 GFS data of $1^{\circ}$ are presented in Figures 12(a-f), respectively. From the figures, it is found that the simulated area averaged high cloud increases continuously from the starting of model run and after a certain time it decreases for the ICs at 0000 UTC of 27, 28, 29 and 30 April 2019 GFS data of $1^{\circ}$. The simulated high cloud is found minimum for YSU and BouLac schemes and maximum for TEMF and MRF schemes for the ICs at 27, 28, 29 and 30 April. The TEMF scheme has simulated maximum high clouds for all 
ICs and for all through the simulation time. The $0.25^{\circ}$ GFS data has simulated higher area averaged clouds than that of $1^{\circ}$ GFS data of TEMF, Shin-Hong, GBM and MRF schemes for the ICs of 27 and 28 April. For other ICs all the PBL schemes have simulated almost similar amounts of area averaged high cloud for $1^{0}$ and $0.25^{\circ} \mathrm{GFS}$ data.
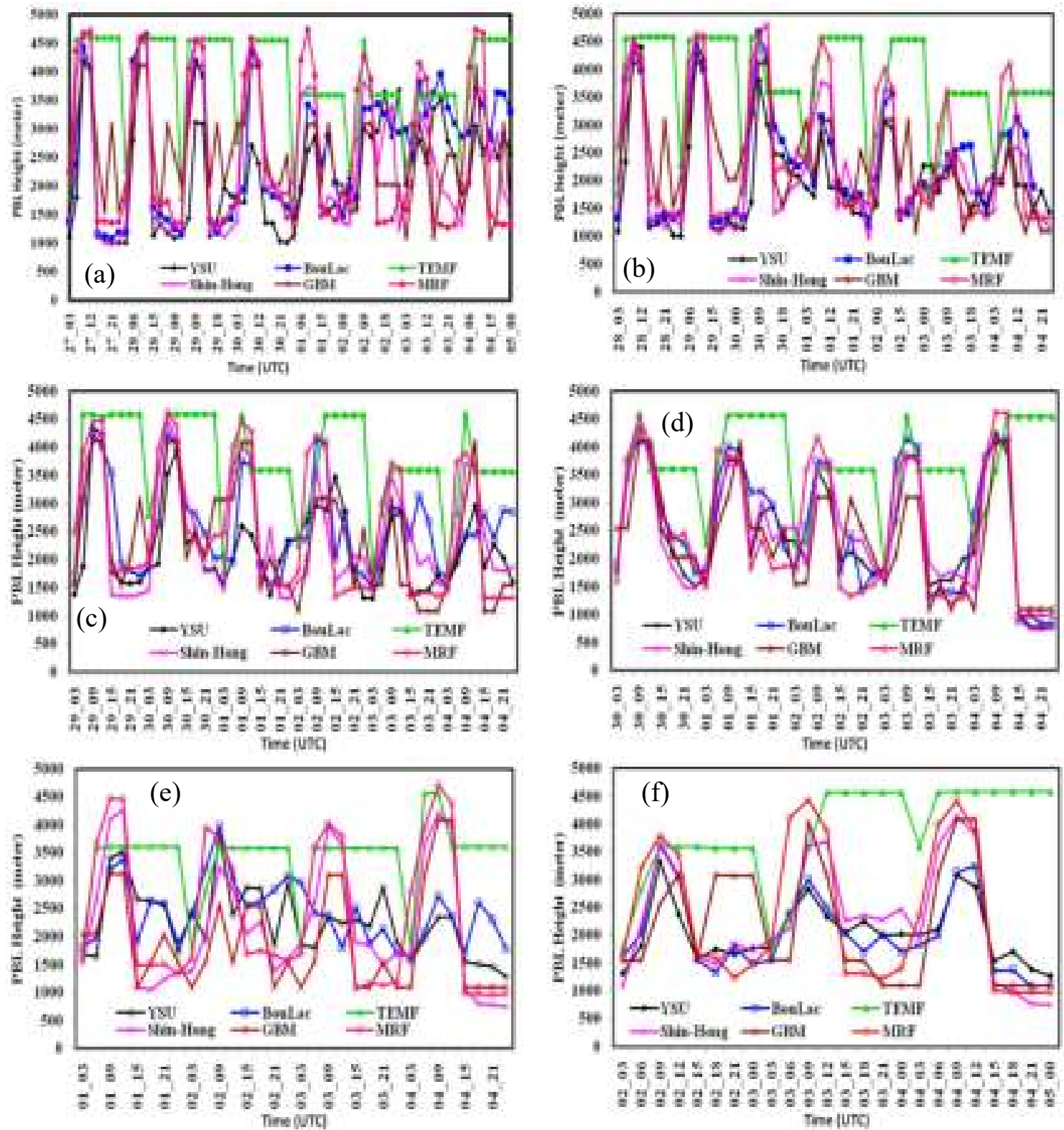

Figure 11: Time series of simulated average PBL height (m) for the ICs at 0000 UTC of (a-d) $27-30$ April and (e-f) 01 - 02 May 2019, respectively for the GFS data of 1 for six different PBL schemes.

The simulated area and time averaged values of high cloud are 27, 28, 36, 32, 34 and 32\% for $1^{\circ}$ GFS data and 27, 27, 36, 34, 36 and $31 \%$ for $0.25^{\circ}$ GFS data for YSU, BouLac, TEMF, Shin-Hong, GBM and MRF schemes, respectively for the initial condition of 29 April. The simulated area and time averaged values of high cloud are $18,16,26,25,27$ and $23 \%$ for $1^{\circ}$ GFS data and $17,16,27,28,28$ and $20 \%$ for $0.25^{\circ}$ GFS data and maximum $37,36,50,42,43$ and $40 \%$ for $1^{\circ}$ GFS data and 36, 33, 45, 44, 44 and 38\% for $0.25^{\circ}$ GFS data for YSU, BouLac, TEMF, Shin-Hong, GBM and MRF schemes, respectively for the initial condition of 29 April. 

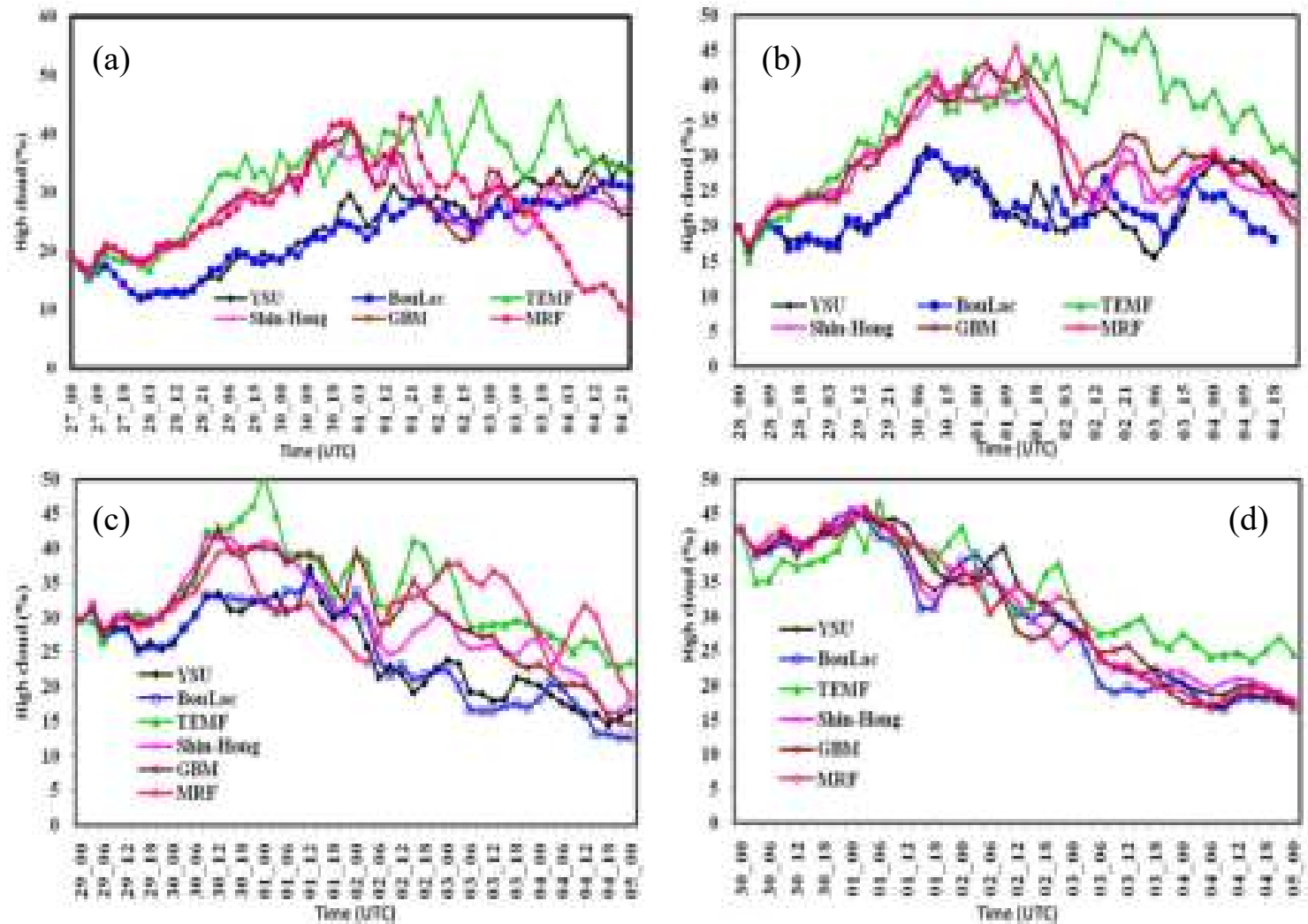

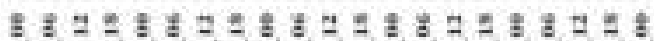

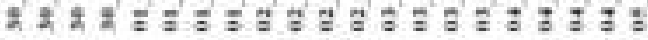
Teneiusc)
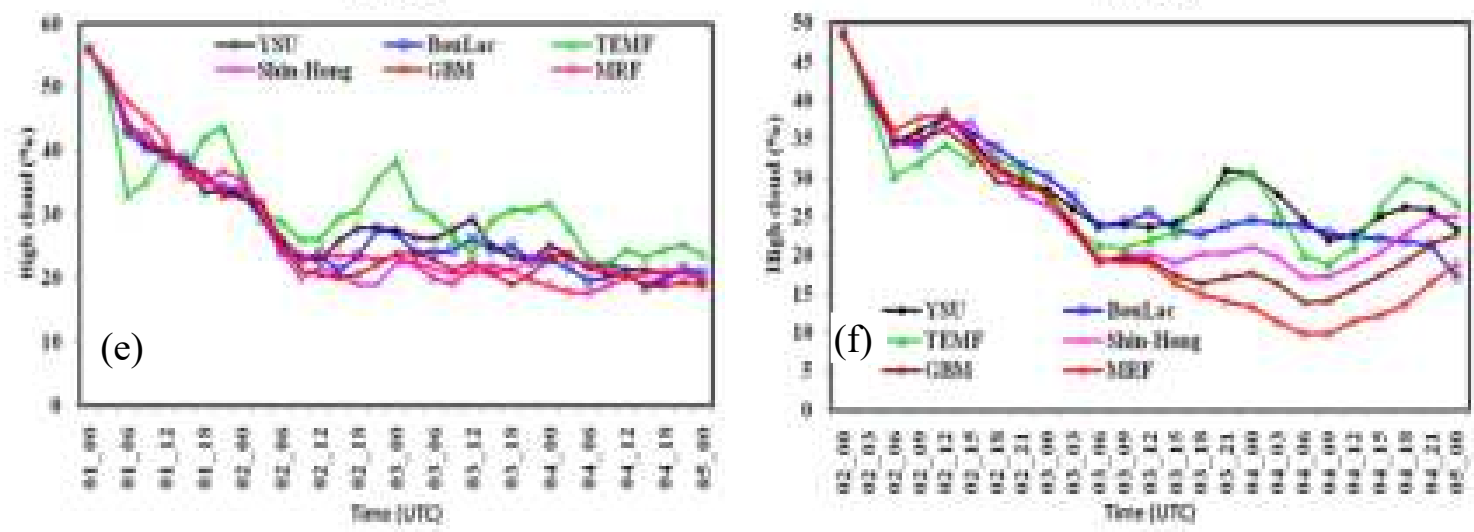

Figure 12: Time variation of simulated area averaged high cloud (\%) for the ICs at 0000 UTC of (a-d) $27-30$ April and (e-f) $01-02$ May 2019, respectively for the GFS data of $1^{\circ}$ for six different PBL schemes.

\section{CONCLUSIONS}

The simulated values of ECP by TEMF scheme are 930, 932, 937, 929, 944 and $932 \mathrm{hPa}$ for the ICs at 0000 UTC of 27, 28, 29, 30 April, and 01 May and 02 May, respectively and observed ECP is $932 \mathrm{hPa}$. From the simulated ECP, it is clearly seen that only the TEMF scheme has been simulated as similar to that of the observed ECP and others are much higher than that of the observed ECP. After the landfall the simulated ECP for almost all PBL schemes followed the trend of observed ECP for $1^{\circ}$ GFS data but the output of $0.25^{\circ}$ GFS data is different than that of observed.

The MWS simulated by the TEMF scheme is almost similar to that of observed MWS at 10m height and all other schemes have simulated much lower MWS. The TEMF scheme simulated values of MWS are 61, 65, 62, 66,56 and $62 \mathrm{~m} / \mathrm{s}$; and $67,61,64,61,60$ and $61 \mathrm{~m} / \mathrm{s}$; for $1^{\circ}$ and $0.25^{\circ} \mathrm{GFS}$ data for the ICs at 0000 UTC of 27 , 28, 29, 30 April, and 01 and 02 May respectively and the observed MWS is $59 \mathrm{~m} / \mathrm{s}$. All other schemes have simulated much lower MWS than that observed.

The simulated area averaged RH is maximum at 0000 UTC and minimum at 0900 UTC every day for all PBL schemes. The pattern is oscillatory and its time period is almost constant. The TEMF scheme has simulated 
much higher temperature at $2 \mathrm{~m}$ height and also lower ECP and higher MWS at 10m height. The simulated ECP and MWS at $10 \mathrm{~m}$ height by TEMF scheme are almost similar to that observed. The amplitude of simulated temperature for other PBL schemes is almost constant from the initial time of simulation to the landfall of TC Fani and their differences are insignificant except for the TEMF scheme. The temperature at $2 \mathrm{~m}$ height is positively correlated with the ECP and MWS at 10m height. The TEMF scheme has simulated significantly higher area averaged potential temperature at $2 \mathrm{~m}$ height than that of other schemes for all the ICs of model run. The crest (trough) of potential temperature oscillation is matched with the crest (trough) of temperature at $2 \mathrm{~m}$ height. The TEMF scheme has simulated significantly higher and MRF scheme has simulated lower area averaged MCAP than that of other schemes for all the ICs of model run. The TEMF scheme has simulated maximum high clouds for all ICs and for all through the simulation time.

The error was systematic for all PBL schemes for the ICs at 0000 UTC on 30 April at $0.25^{\circ}$ and $1^{\circ}$ GFS data but the track error was much less for $1^{\circ}$ GFS data than that of $0.25^{0}$ GFS data. The TEMF scheme has simulated the most deviated track and MRF scheme has simulated less deviated track for all through the simulation. At the time of landfall Shin-Hong scheme has simulated minimum track error for $1^{\circ}$ and $0.25^{\circ}$ GFS data and TEMF scheme for $1^{\circ}$ GFS data with the initial condition at 0000 UTC of 30 April. Among the PBL schemes TEMF scheme has simulated much higher average track error and GBM scheme has simulated lower average track error. The average track error for $1^{\circ}$ GFS data are 73, 82, $111,65,46$ and $59 \mathrm{~km}$ and for $0.25^{\circ}$ GFS data it is 80 , 106, 170, 65, 66 and $60 \mathrm{~km}$ for YSU, BouLac, TEFM, Shin-Hong, GBM and MRF schemes, respectively. The average track error is less for $1^{\circ}$ GFS data output than that of $0.25^{\circ}$ output. The study has shown large variations of track and intensity among the different PBL schemes. The PBL schemes have a major impact on the track and intensity of TC Fani. The intensity simulated by the TEMF scheme is better but the track error is higher than that of other schemes.

\section{ACKNOWLEDGEMENTS}

The author is grateful to the KUET authority for financing the project to complete this research work. The Author is also grateful to National Centre for Atmospheric Research (NCAR), USA for making the WRF (WRF-ARW) model available to modeling community. The Grid Analysis and Display System software (GrADS) was used for analytical purposes and displaying Figures. Bangladesh Meteorological Department (BMD) is acknowledging for providing necessary data over Bangladesh.

\section{REFERENCES}

Angevine, W. M., 2005. An integrated turbulence scheme for boundary layers with shallow cumulus applied to pollutant transport, J. Appl. Meteor., 44, 1436-1452, doi:10. 1175/JAM2284.1.

Angevine, W. M., Jiang H., and Mauritsen T., 2010. Performance of an eddy diffusivity-mass flux scheme for shallow cumulus boundary layers, Mon. Wea. Rev., 138, 2895-2912, doi:10.1175/2010MWR3142.1.

Bougeault, P., Lacarrere P., 1989. Parameterization of orography-induced turbulence in a mesobeta-scale model, Mon. Wea. Rev., 117, 1872-1890.

Braun, S. A., and Tao W. K., 2000. Sensitivity of High-Resolution Simulations of Hurricane Bob (1991) to Planetary Boundary Layer Parameterizations, Mon. Wea. Rev., 128, 3941-3961.

Cohen, A. E., Cavallo S. M., Coniglio M. C., and Brooks H. E., 2015. A Review of Planetary Boundary Layer Parameterization Schemes and their Sensitivity in Simulating Southeastern U.S. Cold Season Severe Weather Environments, Weather and Forecasting, 30, 591-612.

Das, S. K., and Alam M. M., 2019. Study the Impact on Environmental Moisture during the Intensification and Movement of Tropical Cyclone Hudhud in the Bay of Bengal Using WRF-ARW Model, Journal of Engineering Science, 10(1), 31-43

Dong, M., Ji C., Chen F., and Wang Y., 2019. Numerical Study of Boundary Layer Structure and Rainfall after Landfall of Typhoon Fitow (2013): Sensitivity to Planetary Boundary Layer Parameterization, Adv. Atmos. Sci., 36, 431-450. https://doi.org/10.1007/ s00376-018-7281-9

Dudhia, J., 1989. Numerical study of convection observed during the winter monsoon experiment using mesoscale two-dimensional models, J. Atmos. Sci., 46, 3077-3107.

Ek, M. A. A., Mitchell K. E., Lin Y., Rogers E., Grundmann P., Koren V., Gayno G., and Tarpley J. D., 2003. Implementation of Noah land surface model advances in the National Centers for Environmental Prediction operational mesoscale Eta model, Journal of Geophysical Research, 108, D22, 8851, doi:10.1029/2002 JD003296

Grenier, H., and Bretherton C. S., 2001. A moist PBL parameterization for large-scale models and its application to subtropical cloud-topped marine boundary layers, Mon. Wea. Rev., 129, 357-377, doi:10.1175/1520-0493(2001)129,0357: AMPPFL. 2.0.CO;2 
Haney, S. U., Alam M. M., and Akhter M. A. E., 2018. Sensitivity of Microphysics for the Simulation of Heavy Rainfall during 23-26 June 2015 over Bangladesh using High Resolution WRF-ARW Model, Journal of Engineering Science, 9(2), 69-84.

Holt, T., and Raman S., 1988. A review and comparative evaluation of multilevel boundary layer parameterizations for first order and turbulent kinetic energy closure schemes, Rev. Geophys., 26,761-780.

Hong, S. Y., Dudhia J., and Chen S. H., 2004. A Revised Approach to Ice Microphysical Processes for the Bulk Parameterization of Clouds and Precipitation, Mon. Wea. Rev.,132, 103-120.

Hong, S.Y., and Pan H. L., 1996. Nonlocal boundary layer vertical diffusion in a medium-range forecast model. Mon. Wea. Rev., 124, 2322-2339, doi:10.1175/1520-0493 (1996) 124, 2322: NBLVDI.2.0.CO;2.

Hong, S.Y., Noh Y., and Dudhia J., 2006. A new vertical diffusion package with an explicit treatment of entrainment processes, Mon. Wea. Rev., 134, 2318-2341.

Hu, X. M., Nielsen-Gammon J. W., and Zhang F., 2010. Evaluation of three planetary boundary layer schemes in the WRF model, Journal of Applied Meteorology and Climatology 49, 1831e1844. doi:10.1175/2010JAMC2432.1.

Kain, J. S., 2004. The Kain-Fritsch convective parameterization: An update. J. Appl. Meteor., 43, 170-181, Lin, Y.-L., Farley R.D., and Orville H. D., 1983: Bulk parameterization of the snow field in a cloud model, J. Climate Appl. Meteor., 22, 1065-1092.

Kain, J. S., and Fritsch J. M., 1990. A one-dimensional entraining/detraining plume model and its application in convective parameterization, J. Atmos. Sci., 47, 2684-2702.

Kain, J. S., and Fritsch J. M., 1993. Convective parameterization for mesoscale models: the Kain-Fritsch scheme, the representation of cumulus convection in numerical models, Meteo. Monogr, No. 46 Amer. Meteor. Soc., 165-170.

Khan, M.S. and Alam M. M., 2020. Study on Sensitivity of Microphysics for the Simulation of Rainfall for the Month of May 2015 over Bangladesh using High Resolution WRF-ARW Model, Journal of Engineering Science, 11(1), 43-60. https://doi.org/10.3329/jes.v11i1.49546.

$\mathrm{Li}, \mathrm{X}$., and $\mathrm{Pu} \mathrm{Z}$., 2008. Sensitivity of numerical simulation of early rapid intensification of hurricane Emily (2005) to cloud microphysical and planetary boundary layer parameterizations, Mon. Wea. Rev., 136, 4819-4838.

Mlawer, E. J., Taubman S. J., Brown P. D., Lacono M. J., and Clough S. A., 1997. Radiative transfer for inhomogeneous atmosphere: RRTM, a validated correlated-k model for the long wave, J. Geophys. Res., 102(D14), 16663-16682.

Musson, G. L., 1995. Comparison of different simple turbulence closures with a one-dimensional boundary layer model, Mon. Wea. Rev., 123, 163-180.

Sharan, M., and Gopalakrishnan S. G., 1997. Comparative evaluation of eddy exchange coefficients for strong and weak wind stable boundary layer modeling, J. Appl. Meteorol., 36:545-559.

Shin, H. H., and Dudhia J., 2016. Evaluation of PBL Parameterizations in WRF at Sub-kilometer Grid Spacings: Turbulence Statistics in the Dry Convective Boundary Layer, Mon. Wea. Rev., 144, 1161-1177

Shin, H. H., and Hong S. Y., 2011. Inter-comparison of planetary boundary-layer parameterizations in the WRF Model for a single day from CASES-99, Bound.-Layer Meteor., 139, 261-281, doi:10.1007/s10546010-9583-z.

Shin, H. H., and Hong S.Y., 2013. Analysis of resolved and parameterized vertical transports in convective boundary layers at gray zone resolutions, Journal of the Atmospheric Sciences, 70(10), 3248-3261.

Tyagi B., Magliulo V., Finardi S., Gasbarra D., Carlucci P., Toscano P., Zaldei A., Riccio A., Calori G., D’Allura A., and Gioli B., 2018. Performance Analysis of Planetary Boundary Layer Parameterization Schemes in WRF Modeling Setup over Southern Italy, Atmosphere, 9, 272, doi:10.3390/atmos9070272

(C) 2020 The Authors. Journal of Engineering Science published by Faculty of Civil Engineering, Khulna University of Engineering \& Technology. This is an open access article under the terms of the Creative Commons Attribution-NonCommercial-NoDerivatives License, which permits use and distribution in any medium, provided the original work is properly cited, the use is non-commercial and no modifications or adaptations are made. 